\title{
6. Retirement Timing and Social Stratification in Spain
}

\subsection{Introduction}

Continuing with our inquiry into the relationship between social stratification and labour-force withdrawal, in the present chapter, we are interested in unraveling how retirement behaviour in Spain is structured along the dividing lines of gender and social class. One central objective is to disclose potential national peculiarities in the mechanisms governing the transition from work to retirement. Against the background of the recent pension reform's lifting the official retirement age from 65 to 67 years, understanding the determining factors of retirement timing in Spain is more relevant than ever.

In agreement with the conceptual framework of this study, I pursue three main research questions:

1) What are the typical pathways into retirement for Spanish men and women?

2) What types of workers are most likely to retire early?

3) How does the usage of available pathways differ across social groups?

Seeking answers to these questions, I analyse the Spanish Labour Force Survey (Encuesta de la Población Activa) (EPA). As the survey is largely within the framework of the European Union Labour Force Survey (EU-LFS), it allows for direct comparison to Germany. At the same time, the methodology used in this and the next chapter attempts to mimic the one used in chapter 5 as closely as possible. On the basis of a detailed description of the influential institutional arrangements, I analyse micro-level differences in retirement behaviour in Spain. Unlike most previous studies on Spain, women are included in the analysis, and the gender divide is examined explicitly.

In detail, the chapter proceeds as follows: the next section describes the constitution of the Spanish labour market and summarises its main developments since the mid-1970s. I then outline the relevant institutional characteristics of the Spanish welfare state. In particular, I set out how the pension system creates varying incentives to retire early and how labour market regulation lends social protection to employees. On this basis, I formulate a set of hypotheses regarding the patterns of social stratification that we expect to find. After this, I delineate the methods employed in the event-history analysis of retirement behaviour. Using a piecewise constant exponential model, I examine how individual socioeconomic characteristics impact the timing of labour-force withdrawal. Following on from this, I present a series of competing-risks models that discriminate

(cc) BY-NC-ND 
between different pathways to retirement. The results section concludes with an attempt to account for the selection process that shapes the "eligibility" for retirement. For this purpose, a set of duration selection models is carried out as a robustness check for the foregoing analyses. In the final section, I summarise the findings and highlight the particularities of Spanish career-exit processes within the Western European context.

\subsection{Labour Market and Structural Change}

Social change in the last decades has unfolded in Spain at a higher pace than in most other developed countries. Since the end of the Franco regime, each new cohort has acquired a better level of education than the one before, with this pattern translating into an increasingly late entry into first employment (Garrido \& Chuliá 2005). Given the speed of structural change and of educational expansion, "it can be argued that Spain has shifted almost directly from an agricultural to a post-industrial society" (Bernardi \& Garrido 2006: 122). Nevertheless, the skill level of the Spanish labour force is still low in comparison with most affluent societies. In terms of its class structure, Spain is also characterised by a high proportion of self-employed and small employers. Occupational boundaries are not very pronounced, as the flexibilisation of the employment system via temporary contracts has occurred across the board, albeit it mainly affects younger cohorts (Polavieja 2005). Labour-force participation among women is still low by international standards, but it is steadily rising.

The Spanish economic expansion that lasted from the mid 1990s until the current recession has been outstanding in Western Europe, comparable only to the upsurge of the Irish economy. However, Spain's economic model, based on cheap labour, now finds itself under pressure. as manufacturing in the globalised economy is increasingly relocated to developing countries with lower social and ecological standards (Buchholz et al. 2006). At the same time, the heavy weight of the construction sector and tourism in national GDP has proven particularly problematic in times of economic recession. This vulnerability was painfully evidenced in the two employment crises, of 1977-85 and 1991-94. While the better educated were largely sheltered from labour market pressures, a huge number of low-skilled workers lost their jobs (Garrido \& Chuliá 2005). This disparity can be seen as a consequence of the dual nature of the Spanish labour market.

In the last ten years, there has been a massive wave of immigration to Spain, without precedence in a country with a negative migration balance during most of the twentieth century (Cebolla \& González 2008). The inflow of numerous young migrants with high economic activity rates (Moreno 2009) has also helped to stall the process of population aging in Spain, notwithstanding Spain's low 
rate of reproduction. The old-age dependency ratio therefore will not increase as rapidly as in other countries during the next twenty years; it is rather projected to reach peak levels after 2040 (Muñoz et al. 2007: 63). By 2050, then, Spain will probably have one of the oldest populations in the world. Because immigrants are still relatively young, they do not play a role in retirement yet.

\subsection{Institutional Context}

\subsubsection{General Features of the Spanish Welfare State}

Although the Spanish system of social welfare has undergone profound changes in the last decades, the foundations laid by the Franco regime are still largely intact. Characteristically, decommodifying social policies, which would grant access to economic resources independent of work, were largely absent in predemocratic times. Instead, state intervention in the labour market took place mainly through the guarantee of stable employment for the male breadwinner (Lessenich 1995, 1996). The rapid modernisation of welfare policies after the dictatorship was characterised by the flexibilisation of employment legislation. Nonetheless, the Spanish welfare state is still less developed those in many other Western European countries (Navarro 2009).

During the transition to democracy, trade unions regained their strength in the corporatist framework. Although union density is only around $10-15 \%$, the coverage of collective bargaining is about 70\% (Palanzuela $\&$ Jimeno 1996). Wage setting is largely decentralised, though, with collective bargaining mostly taking place at the branch level within provinces and regions (Hipólito et al. 2005).

Since the 1980s, the main trademarks of the Spanish labour market have been high rates of unemployment and fixed-term contracts, which produce a particularly poor employment situation of young adults (Martínez et al. 2009). Health care is tax financed and provides universal coverage. In order to improve social protection against frailty, a new system of long-term care was introduced in 2007, albeit with serious initial problems. As set out in the second chapter of this study, the Spanish welfare system is conventionally classified as a fragmented welfare regime (Ferrera 1996).

\subsubsection{Pensions and Retirement Incentives}

Article 41 of the Spanish constitution from 1978 codifies the principle of universalism in the system of social security. In terms of old-age pensions, it 
proclaims that the state guarantees the subsistence of its citizen in the third age via adequate pensions (Herce 2003: 195 f.). In this sense, it is no coincidence that Spanish welfare expenditures are characterised by a heavy orientation towards the elderly (cf. Lynch 2001).

An encompassing legal framework of social welfare was not established in Spain before 1967 with the introduction of the Régimen General de la Seguridad Social (RGSS). This defined-benefit system, which replaced the fragmented corporatist system of mutualidades, is financed on a pay-as-you-go basis. It covers all dependent employees in the public and private sectors. ${ }^{74}$ Based on concerted action involving corporate actors and all major parties, in 1996, a reform proposal called Pacto de Toledo became the blueprint for a series of important modifications of the social-security system (cf. Alarcón 1998; Chuliá 2000). It established a mechanism for the price indexation of pension benefits and a clearer separation between the contributory and non-contributory elements of the pension system.

The social-insurance-style pension system in Spain puts major weight on the contributions of the last 15 years prior to retirement. The earning-related contributions during this period determine the regulatory base in the calculation of pension benefits. The other two main elements of the pension formula are the total number of working years and the age of retirement (see below). On the condition of having contributed at least 15 years to the social-security scheme (two of which have to be incurred within the previous 15 years), a person who retires at the statutory retirement age of 65 years is entitled to $50 \%$ of the regulatory base. ${ }^{75}$ For each additional year of contribution between 15 and 25 years, the regulatory base increases by three percentage points. Beyond this point, each additional year is worth two percentage points until $100 \%$ are reached at 35 pensionable years.

There have been four major pension reforms during the last thirty years. Reacting to increasing financial pressure, the reform of 1985 introduced several cost-reducing elements. The already-mentioned minimum number of years of contribution to qualify for pension eligibility was raised from ten to fifteen years. At the same time, the contribution period considered to calculate benefits was broadened from two to eight years to stop the common practice of "pension buying" through strategic wage increases in the last years of service.

74 There are still special rules for miners, farmers, agricultural workers, seamen, home workers, and the self-employed, as well as for civil servants (cf. Maldonado 2002: 393419). Moreover, there is special treatment of high-risk occupations, such as firemen and bullfighters (Spina 2008: 159 f.).

75 This description refers to the legislation pre-2013, when the most recent pension reform started to be rolled out. 
Moreover, the reform restricted access to disability pensions after the number of beneficiaries had seen an increase of 80\% within eight years. The 1997 reform extended the calculation period for the regulatory base to 15 years and enhanced survivor pensions. The reform of 2002 has been especially important in terms of work incentives in late careers, as it establishes the current system of adjustment factors. As a recent study by the Bank of Spain shows, it implied an overall reduction of early-retirement incentives and greater actuarial fairness (Vegas et al. 2009: 17). As a consequence, the pension benefits of workers who retire before the official retirement age of 65 years are reduced by a rate of $6 \%$ to $8 \%$ per year of anticipation, depending on the number of contribution years. ${ }^{76}$ Finally, the 2011 reform raised the statutory pension age from 65 to 67 years and amplified the calculation period from 15 to 25 years. However, this latest change in legislation only begins to take effect in 2013 is thus not relevant for the present study. The description provided here refers to the situation until 2013.

Table 6.1 shows how the pension level, relative to the regulatory base, varies with pension age and the number of working years. The incentives to stay on the job until age 65 are substantial thanks to the strict penalisation of early retirement. Moreover, it becomes obvious that the system is far from a principle of contributory equivalence. For instance, a worker who retires at age 61 after having worked for 40 years receives a lower pension than a worker with the same wage who retires at age 65 after having contributed for 25 years. The system thus penalises workers that enter the labour market early.

For each year worked beyond age 65 , the regulatory base for pension benefits of workers with at least 35 years of social security contributions is further topped up by two percentage points (three points for those having reached 40 pensionable years at age 65 ). In addition, social security contributions of employees over 60 years with more than five years of seniority are reduced by $50 \%$ and diminish gradually thereafter until entirely abolished at 65 years of age. Employers' contributions for workers over 55 years of age are reduced, too. Moreover, reforms improved the financial conditions for gradual retirement through the introduction of more flexible ways to combine pension payments and income from work. However, the implementation of these measures eventually depends on collective agreements between the social partners.

Generally, pension benefits are capped at a maximum of some 33,000 Euros annually (threshold in 2008). For insured persons entitled to receive an old-

76 By and large, the new framework transfers to the younger cohorts the pension rules in place until that point for older workers, who still had contributed to the pre-1967 system of mutualidades. 
Table 6.1

Relative Pension Level by Working Years and Retirement Age.

\begin{tabular}{|l|c|c|c|c|c|}
\hline \multirow{2}{*}{$\begin{array}{l}\text { Years Contributed } \\
\text { at Retirement }\end{array}$} & $\begin{array}{c}\text { Adjustment } \\
\text { for Anticipated } \\
\text { Retirement p.a. }\end{array}$ & $\begin{array}{c}\text { Retirement } \\
\text { at age } \\
61\end{array}$ & $\begin{array}{c}\text { Retirement } \\
\text { at age } \\
63\end{array}$ & $\begin{array}{c}\text { Retirement } \\
\text { at age } \\
65\end{array}$ & $\begin{array}{c}\text { Retirement } \\
\text { at age } \\
67\end{array}$ \\
\cline { 3 - 6 } & 8 & 34 & 42 & 50 & 50 \\
\hline 20 & 8 & 44.2 & 54.6 & 65 & 65 \\
\hline 25 & 8 & 54.4 & 67.2 & 80 & 80 \\
\hline 30 & 8 & 61.2 & 75.6 & 90 & 90 \\
\hline 32 & 7.5 & 65.8 & 79.9 & 94 & 94 \\
\hline 35 & 7 & 72 & 86 & 100 & 104 \\
\hline 37 & 6.5 & 74 & 87 & 100 & 104 \\
\hline 40 & 6 & 76 & 88 & 100 & 104 \\
\hline 45 & 6 & 76 & 88 & 100 & 106 \\
\hline
\end{tabular}

Source: own elaboration.

age pension, very small pension benefits are topped up to reach a minimum pension. Its level has been improved considerably in recent years by the leftist government to reach a yearly amount of 7,399 EUR in 2008. ${ }^{77}$ Besides, there exists a means-tested scheme of non-contributory pensions for persons older than 65 years or permanently disabled persons older than 60 years who are not entitled to an ordinary pension. In 2010, this benefit, which is incompatible with other incomes, amounts to 4,755 EUR yearly. ${ }^{78}$ All pensions are taxed, but they are exempt from social security benefits.

Notably, the fixating of mandatory retirement at 65 years in collective agreements between the social partners was legal until 2001. Since then, mandatory retirement clauses in collective agreements have been nullified. However, agreements that were effective then remain in place until expiration (cf. Hernández 2005).

77 The amount refers to a person older than 65 years without a dependent spouse. For younger retirees, the corresponding yearly amount is 6,895 EUR. In the presence of a dependent spouse, the amount is increased by $25 \%$.

78 For contributors to the pre-1967 system, there still exists an alternative minimum pension scheme, the Seguro Obligatorio de Vejez e Invalidez (SOVI). 
Private and occupational pensions only play a minor role in Spain. The public pay-as-you-go pension scheme is still rather monolithic as regards oldage provision in Spain. The market for financial products of old-age provision was established in 1987, and the fiscal treatment of private pension plans has changed several times thereafter (Fundación de Estudios Financieros 2008). However, there has not been a major pension reform at the scale of other European welfare states. Occupational pensions are usually defined contribution plans, and the great majority are taken out in the form of lump-sum payments (OECD 2008: 274). De facto, the Spanish pension system is still largely a singlepillar system (OECD 2005a: 170). For instance, the coverage of occupational pensions was only approximately $8 \%$ in 2006.

\subsubsection{Institutional Pathways into Retirement}

Figure 6.1 gives an overview of the most relevant retirement pathways in contemporary Spain. Besides the standard old-age pension, which is accessible at age 65 , there are a number of early-retirement options available to workers under certain conditions. For example, a special pension allows for retirement at 64 years without actuarial reductions if the position gets filled with an unemployed person. This pension type aims at fostering the generational turnover in qualified medium and large firms.

Alternatively, anticipated pension benefits are granted to workers at 61 years of age after they have been unemployed for at least six months. ${ }^{79}$ Older workers who contributed to the pre-1967 system are entitled to an anticipated pension from age 60 onwards. In either case, adjustments of $6-8 \%$ are imposed on the benefit for each year that remains until the standard pension age of 65 years. Special conditions apply to workers in dangerous occupations and to handicapped persons, for whom the effective age boundary is lowered as a function of the years of contribution and, if applicable, the degree of the handicap, but never below 52 years of age.

There are different forms of disability pensions that have no minimum age. Coverage is high, while expenditures are about OECD average. In a country characterised by a high share of semi- and unskilled workers with high exposure to job-related hazards, the disability scheme is important. "Moreover, disability and sickness benefits are relatively well integrated - ensuring adequate

79 To qualify for this pension, the state of unemployed must not be caused voluntarily on behalf of the workers. Yet, opting for retirement in case of economic restructuring of the employing company (ERE) is always considered involuntary, as the cease of the work contract is beyond the worker's control. 


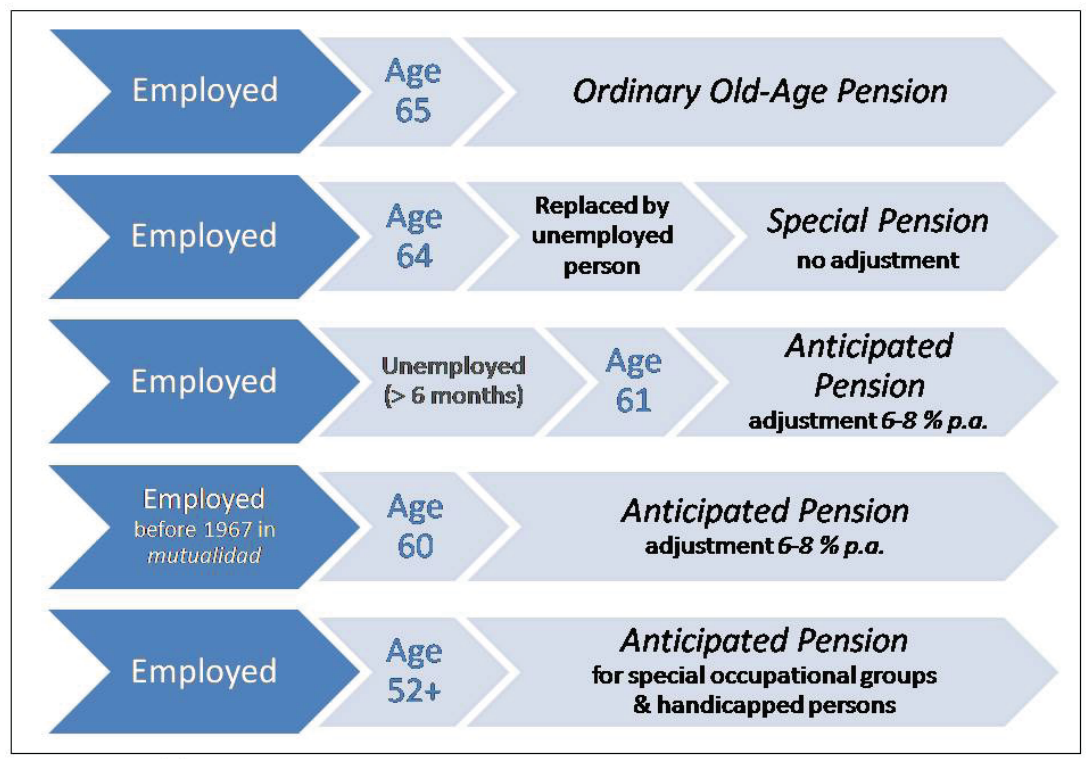

Source: own elaboration.

Fig. 6.1. Overview of Pathways into Retirement in Spain.

connection between the two pillars" (OECD 2003: 71). Although monitoring and controls have been reinforced in recent decades, there are still indications of some misuse of disability payments as retirement bridging benefits (ibid.).

\subsubsection{Unemployment Benefits and Labour Market Flexibilisation}

Spanish unemployment insurance is contribution-based. It grants earningsrelated benefits for a period between 3 and 24 months, depending on the prior period of contribution. The minimum required contribution period is one year. The amount of unemployment benefits depends on the number of children and decreases by some $14 \%$ after the first six months of receipt. At the same time, the legal framework also establishes a minimum and maximum level of unemployment benefits. The net replacement rate according to OECD estimates is close to the European average at $67 \%$ for an average production worker (OECD 2006b: 60).

Because of the ongoing crisis, the government has temporarily set up an extraordinary, means-tested transfer scheme (paying 400 EUR) for long-time unemployed persons whose unemployment benefits have run out. Persons without sufficient income who are not eligible for unemployment benefits can 
also resort to the social-assistance scheme (Renta Activa de Inserción). ${ }^{80}$ The threshold used for means-testing is equivalent to $75 \%$ of the minimum wage, which is fixed at 624 EUR a month as of 2009. The benefit level is currently at 422 EUR a month. ${ }^{81}$ Part of the scheme is targeted at long-term unemployed persons and return migrants older than 45 years. Active job searching is required, the final objective being re-integration into the labour market. The maximum period of payment is eleven months. Besides, there also exists a special means-tested scheme for unemployed persons over 52 years of age. The benefit level is equal to the general social assistance, but its may last until the standard pension age of 65 is reached. Therefore, it has been subject to heavy criticism by the OECD (2003: $71 \mathrm{ff}$.), which demands better enforcement of the job-search conditions: "All too often," it notes, "this special system is regarded as a pre-retirement scheme" (OECD 2003: 13).

Employment protection legislation has been historically strong in Spain (OECD 2006a: 72). While the conditions of entry into permanent employment have been subject to drastic flexibilisation (Lessenich 1996; Polavieja 2005; Martínez et al. 2009), employment security among elderly workers is still considerable. For instance, compulsory severance payments correspond to 45 days per year of seniority in the standard employment contract (prior to the 2012 labour reform). Employers that due to economic restructuring lay off elderly workers aged over 55 years must continue paying the applicable pension contributions until they turn 61. Note in this context that age-wage curves are steep in Spain, as compared to other developed countries, hence pointing to a persisting principle of seniority payment (OECD 2006a: 66).

Meanwhile, the 1997 reform introduced the possibility to hire persons belonging to particularly vulnerable groups under less favourable conditions and reduced employers' social security contributions for workers over 45 years of age (OECD 2003: 60). With respect to lifelong learning, Spain ranks close to the European average. According to Eurostat data from 2007, 10.4\% of Spanish workers aged 24-64 have received education or further training in the four weeks of reference (EU-15: 10.9\%; EU-27: 9.6\%).

80 The Public State Employment Service gives an overview of these and other forms of benefits at the following site: <http://www.inem.es/inem/ciudadano/prestaciones/guias/ index.html> (version 23 April 2009).

$\mathbf{8 1}$ The reference index IPREM is not indexed automatically but updated annually with the general budget. Since its creation, its nominal increase has been below the rate of inflation and below the increase in the minimum wage. 


\subsection{Hypotheses}

Who is most likely to retire early? What kind of workers are expected to withdraw from the labour market most frequently via risky pathways? In section 5.2.1 we have formulated a series of hypotheses on expected individual-level variation in retirement behaviour. The universe of analysis was the whole of Western Europe in that case, but in principle, the same theoretical claims should also be applicable to the Spanish case. However, based on the idiosyncrasies of the national context described in the foregoing sections, some further considerations shall be made with respect to differential retirement behaviour in Spain.

\subsubsection{Gender}

It has been stated in chapter five that the question of gender disparities in retirement timing is essentially an empirical one, since theoretically, we can arrive at diametrically opposed arguments, depending on the relative importance attributed to four different aspects: (a) sex-based occupational segregation and (b) gendered retirement preferences on the one hand; and (c) pension-oriented work incentives and (d) selection effects on the other.

With regard to the first two factors, i.e. those that contribute to the earlier retirement of women, the picture is ambivalent. By international standards, Spain is characterised by a relatively low degree of occupational segregation (OECD 2002a: 90).82 Moreover, we saw in chapter 4 that gender differences in retirement attitudes are not particularly pronounced. Concerning the other two factors, i.e. those that foster a later female retirement, we know that women in Spain are characterised by markedly low pension benefits and that the gender divide on the labour market is highly salient (Garrido 1992). In conclusion, since both factors off-set the conventional gender gap in retirement timing, we expect the difference between the retirement ages of men and women to be relatively small. In fact, this has been one of the findings of the previous chapter (cf. sections 5.5.1 and 5.5.4), but given the low number of cases for single countries in SHARE, this central issue still merits further testing.

$\mathbf{8 2}$ The value calculated by the OECD for the dissimilarity index is 0.53 . Note, however, that the incorporation of women into the labour market during the late 1990s has mostly taken place in "female" occupations (Maté García et al. 2002: 91), so it seems likely that gender segregation will increase in the future. 


\subsubsection{Social Class}

The hypotheses relating to social class have been summarised in table 5.1B. On a very general level, we expect service-class employees to retire later than working-class individuals. Their human capital endowment makes it generally less likely for high-skilled workers to be pushed out of the labour market than for low-skilled workers. Further it has been demonstrated in chapter 4 that the salariat embraces age norms which are more favourable towards late exit than the working class.

Generally, we expect the same pattern for Spain, but there are two reasons to assume that this gap is even more accentuated here than in other countries. First, as set out above, the Spanish pension system provides strong work incentives for high-wage earners who have typically completed a relatively short employment career when they reach the retirement corridor. Second, the financial penalties that go along with early uptake of a public pension are quite harsh, such that pull factors in retirement decisions should be less prevalent vis-à-vis push factors than in countries with more generous early exit schemes. Conversely, the minimum pension produces moral hazard for low-wage earners who are not able to increase their pension benefits by working a couple of additional years (Vegas et al. 2009: 22). Therefore, we hypothesise pronounced class differences in retirement behavior in Spain, with working-class individuals withdrawing far earlier than service-class individuals.

Beyond the question of mere timing, the idiosyncrasies of the Spanish system of social welfare also have implications for the risk of being forced to follow a precarious pathway into retirement. Since employment protection is high among Spanish elderly workers, there should be little pressure to leave the labour market involuntarily for a majority of the elderly work force. At the same time, however, unemployment rates are exceptionally high, and the occupational structure, heavily dependent on construction and tourism, is likely to produce an elevated share of vulnerable workers. The upshot is that we expect to observe a high incidence of early retirement transitions that are a consequence of either unemployment or disability among labour market outsiders. The polarisation inherent in the system of social welfare furthermore leads to the hypothesis that workers in routine occupations are much more exposed to this kind of latecareer risks than highly skilled workers.

As set out above, another special feature of the Spanish occupational structure consists in the exceptionally high share of self-employed workers. Although this is partly to do with the country's economic structure itself, it could be argued that many tasks that are exercised by dependently employed workers in other countries are exercised by self-employed workers in Spain. To the extent that work-exit trajectories are circumscribed by task-specific risks, such as safety hazards, these self-employed workers should behave similar 
to employees performing the same tasks in other countries. This leads to the question as to how far the large size of this peculiar class affects its average behavior by means of selection effects. The estimates presented in section 5.5.4 tell us that the Spanish self-employed retire about as late as their counter parts abroad. However, given the limited size of the Spanish SHARE sub-sample it is well worth revisiting this hypothesis using the EPA data. Do the Spanish self-employed, despite their multiplicity, stay in the labour market as long as elsewhere?

Finally, given the high level of female inactivity, the issue of class-gender interactions is particularly interesting in the Spanish context. Are women in an inferior position to men when it comes to involuntary employment exit, even when comparing workers within broad occupational groups (i.e., controlling for social class)? Or do Spanish women on the labour market increasingly behave (and are being treated) like men as the less "fit" females tend to restrict their work to the household? Vice versa, an interesting task of this chapter will be to examine in how far class effects on retirement timing differ between the sexes. Moreover, being lower in seniority probably also contributes to a heightened risk among women of exiting the labour market involuntarily (Flippen \& Tienda 2000).

\subsection{Results}

\subsubsection{Data and Methods}

The empirical analyses in this chapter rely on the 2006 edition of the Spanish Labour Force Survey (Encuesta de la Población Activa) (EPA). Within the framework of the European Labour Force Survey (EU-LFS), a special module on retirement issues was implemented in 28 national European labour-force surveys, using the common questionnaire designed by Eurostat. The module features a number of retrospective questions on careers and the transition to retirement as well as attitudes towards life-long learning, gradual retirement, etc. Only those aged 50-69 years who were either in the labour force in the reference week or had been (self-)employed at age 50 were eligible for the module. Every sixth respondent of the main labour-force questionnaire was also handed out the modular questionnaire.

In order to examine the socio-demographic characteristics related to early and late exit, respectively, I estimate a series of piecewise-constant exponential models (see section 5.3.2 for more details on this method). While the general survival-analytical observation window opens at age 50 and closes at age 69, for reasons related to missing data (see next paragraph), the multivariate models are conducted only for the ages 58-65 years. The corresponding sample size 
is 5,626 individuals. Retirement is defined as permanent exit from the labour market. Work-exit events are correspondingly observed for persons who selfclassified as "retired" or "disabled or permanently sick." Moreover, retirement ages are registered for persons that were otherwise subjectively inactive in 2006 if their last job ended after age 50 and they had no intent to return to work. Respondents who were still employed at the time of the interview are treated as censored. Censoring also affects unemployed and inactive persons (home workers or otherwise inactive) who expressed the intention to return to work. Consistent with the adopted definition of retirement (see section 3.3.1), the survey module's methodology does not sample persons who are economically inactive at age 50. Furthermore, respondents with less than fifteen lifetime years of work in 2006 and less than 10 (approximated) working years at age 50 have been excluded from the analyses.

Social class is measured according to the ESeC schema (Rose \& Harrison 2007). Operationalisation in the EPA is based on the Spanish National Classification of Occupations CNO-94, which bears great similarities to ISCO-88. Unfortunately, the occupational codes are only available at the two-digit level, which inevitably induces some noise in the measurement of class. Class membership for retirees refers to the characteristics of the last job. However, information on previous jobs is only available if retirement took place within the eight years immediately prior to the interview. We therefore estimate the multivariate models only for the interval between 58 and 65 years of age, as otherwise, many of the older respondents who retire early would drop out of the estimations. ${ }^{83}$ This age window captures the great majority of retirement events occurring during the whole twenty-year period, while preserving a balanced cross-sectional sample of retrospective life histories. ${ }^{84}$ As anticipated in section 3.3.2, an eight-class version of $\mathrm{ESeC}$ is used in most of the chapter. It is collapsed into a six-class scheme in section 6.5 .4 because of space limitations.

Industry is operationalised on the basis of the 2-digit National Classification of Economic Activities (CNAE-93). The variable is subject to the same restrictions in terms of retrospective information as is occupation. The number of years worked refers to all periods of work for pay. It is transformed into a time-dependent variable by assuming stable employment between age 58 and retirement. In terms of the highest level of educational attainment, five categories are distinguished: less than primary education, primary education, vocational training, secondary education, and tertiary education.

$\mathbf{8 3}$ To be accurate, the considered on-risk period sets in just before respondents turn 58 and ceases just before they turn 66.

$\mathbf{8 4}$ Specifically, 70\% of observed transitions for which we have full information fall into the analysis window. 
Family situation is measured by a categorical variable that combines marital status and the employment status of the spouse, which is assessed at the household level. That is, the recent employment history of the spouse is taken directly from his or her own data file. As participation in the EPA is compulsory, the fraction of missing spouses is very small, such that their employment status could be even implemented into the person-year file in time-dependent form without great difficulties. For marital status, constancy was assumed during the eight years of the analysis time.

\subsubsection{Descriptive Results}

Let us start the data analysis with a glance at the evolution of retirement patterns in Spain during the last decades. Figure 6.2 shows the employment rates of men for selected birth cohorts during their late careers phase (age 50-80). Unlike most other OECD countries, where the standardisation of career-exit ages was one of the characteristics of the Golden Age of the 1950s and 1960s (Kohli et al. 1991; cf. Han \& Moen 1999), the retirement age of 65 was not normalised in Spain until the mid-1980s (cf. Sánchez 2003: 229). Before that, many people had to work longer. In this sense, it is evident that Spain has been a late-comer in terms of economic development in Western Europe. According to a report from 1975, the mean retirement age then was around 67 years (Informe GAUR, cited in Sánchez 2003: 230).

Spain sees a trend towards early retirement later than most Western European countries and at a comparatively high level. While in 1976 nearly 30\% of the birth cohort 1906-10 had still been employed at 66-70, in 1986, less than $10 \%$ of men born ten years later were employed. The lowest employment rates of older male workers are observed for the 1936 to 1940 birth cohort, that is, those born during the Spanish civil war. Notably, right before the current crisis, another turnaround in the development seemed to be happening. In comparison with the foregoing cohorts, men born between 1941 and 1945 exhibit considerably higher employment rates. Upon censoring, the youngest observed cohort (194650) appears to continue in this trend. The current prolongation of working life in Spain is probably due to recent welfare reforms and rising levels of educational attainment.

Figure 6.3 plots the survival curves of employment exit for men and women. We see that the survival curves of men and women are strikingly similar. It is worth inspecting the course of the retirement process in some more detail, as it corresponds quite closely to the legal framework of old-age pensions set out above. Labour-force activity starts to fall from age 50 at a rather steady pace until age 60, where we observe the first increase in decline in survival rates. This can be explained by workers' eligibility for the old-age pension for those 


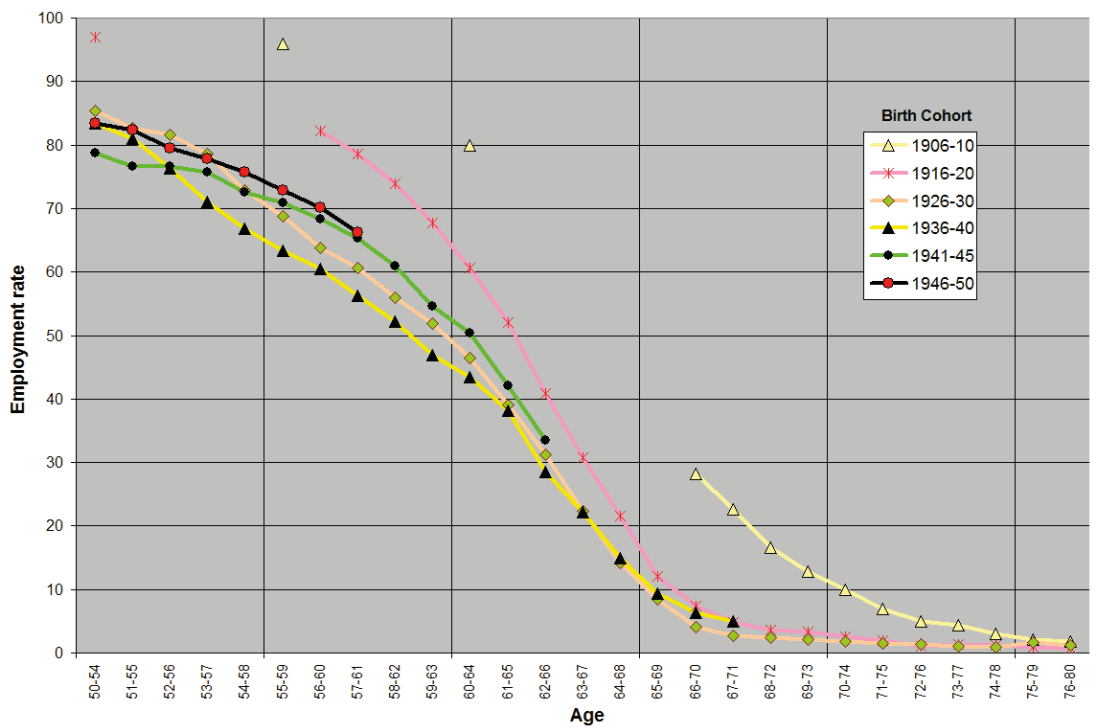

Source: EPA 1976-2008, taken from Radl \& Bernardi (2011).

Fig. 6.2. Men's Employment Rates During Late Career, by Birth Cohort.

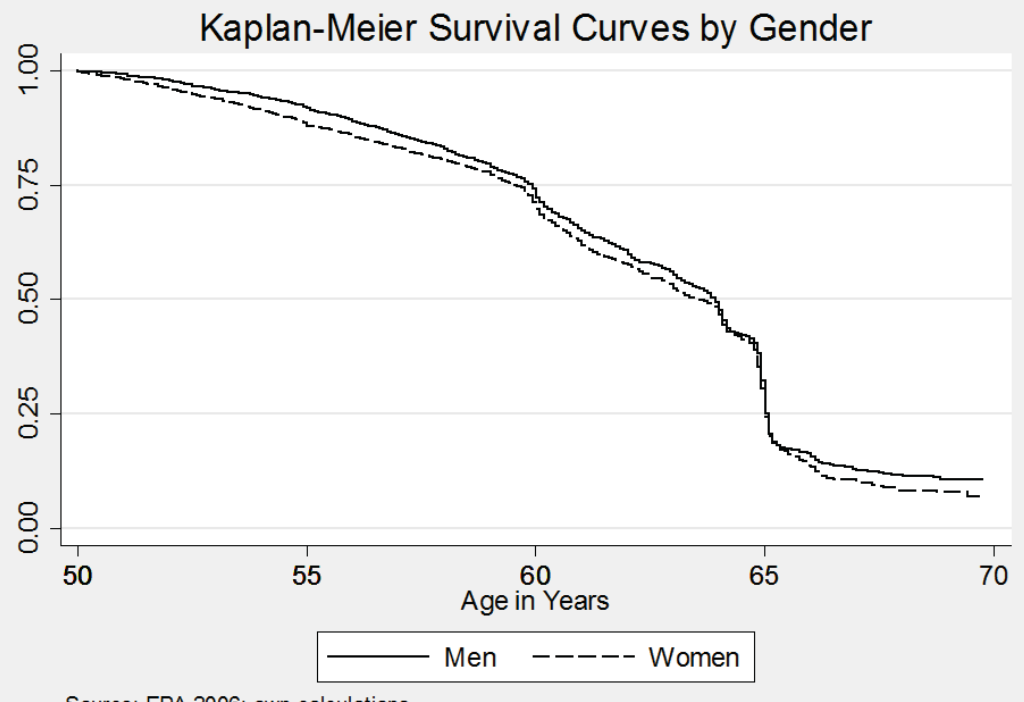

Source: EPA 2006; own calculations.

Fig. 6.3. Survivor Functions of Employment Exit in Spain, by Gender, 2006. 
who contributed to the pre-1967 system. Alternatively, in order to qualify for pension receipt at age 61, younger workers need to have been unemployed for at least half a year, hence they leave work from age 60 onwards as well. After this point, the survival curve continues to fall almost linearly until age 64, when certain workers can opt for the special old-age pension involving generational replacement at the workplace. The most concentrated surge of employmentexit transitions occurs at the standard retirement age of 65 , when no special criteria (other than the minimum contribution period of 15 years) have to be met to receive an old-age pension. The incentive-coherent peaks in the retirement process are illustrated once again in figure 6.4, which shows a plot of the smoothed hazard function.

The difference between men and women is significant according to the cox test, but not particularly sizeable. The slope of the survival curves is almost identical, too. The small magnitude of the gender gap runs counter to conventional wisdom, which tends to think of retirement in terms of employment rates (e.g. Kim 2009). Yet it has already been argued in the previous chapter that the relation between retirement and employment participation is somewhat dialectical. As a matter of fact, Spanish women's general labour-force participation is still considerably behind men's. Economically active women in Spain are a highly selective group, which explains why they stay in work nearly as long as men. Some women may withdraw late from the labour market precisely because of their earlier employment interruptions. Luis Garrido has referred to

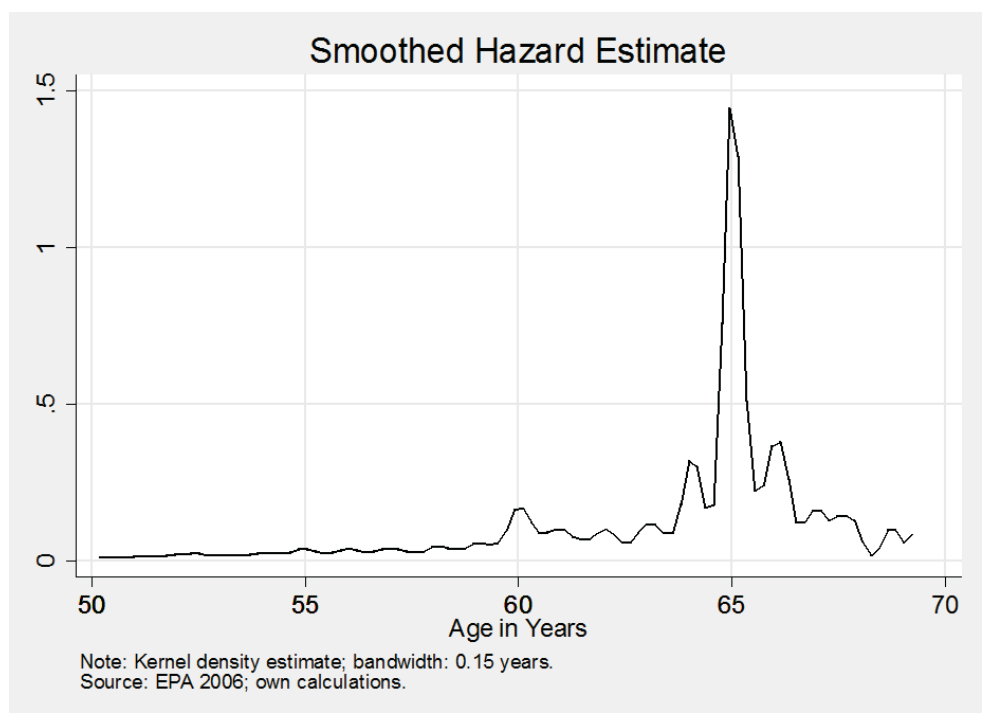

Fig. 6.4. Smoothed Hazard Function, Employment Exit, Men and Women. 
this polarisation of productive behaviours between highly-educated active (and often single) women on the one hand and less-educated inactive (and married) women on the other as the "two female biographies" in Spain (Garrido 1992).

Since women's pension entitlements are normally lower at each given age because of unsteady employment careers, they also have stronger financial incentives to postpone retirement (cf. Alonso \& Pérez 2003: 136). This leads to a higher retirement age among women who work past the childbearing phase (Muñoz et al. 2007: 110). This selection effect, which counterbalances women's general disadvantage in the labour market, was already observed for Spain in the 1970s (cf. Sánchez 2003: 230).

As discussed above, the existing literature has pinpointed the importance of education for the length of working careers (Garrido 1992; Garrido \& Chuliá 2005: Bernardi \& Garrido 2006; Pérez 2006: 206). Late retirement is more frequently observed among highly educated employees than among less educated workers. To inspect this relationship in greater detail, the next graphs (figures 6.5 and 6.6) show Kaplan-Meier survivor functions by level of educational attainment, for men and women separately.

Among men, the level of education clearly matters for the timing of retirement. Virtually throughout the whole observation period, men with tertiary education display a higher labour market attachment than men with a lower level of educational attainment. The gap to the less educated is especially pronounced after the official retirement age of 65 years; at age 69 , some $20 \%$ of people with

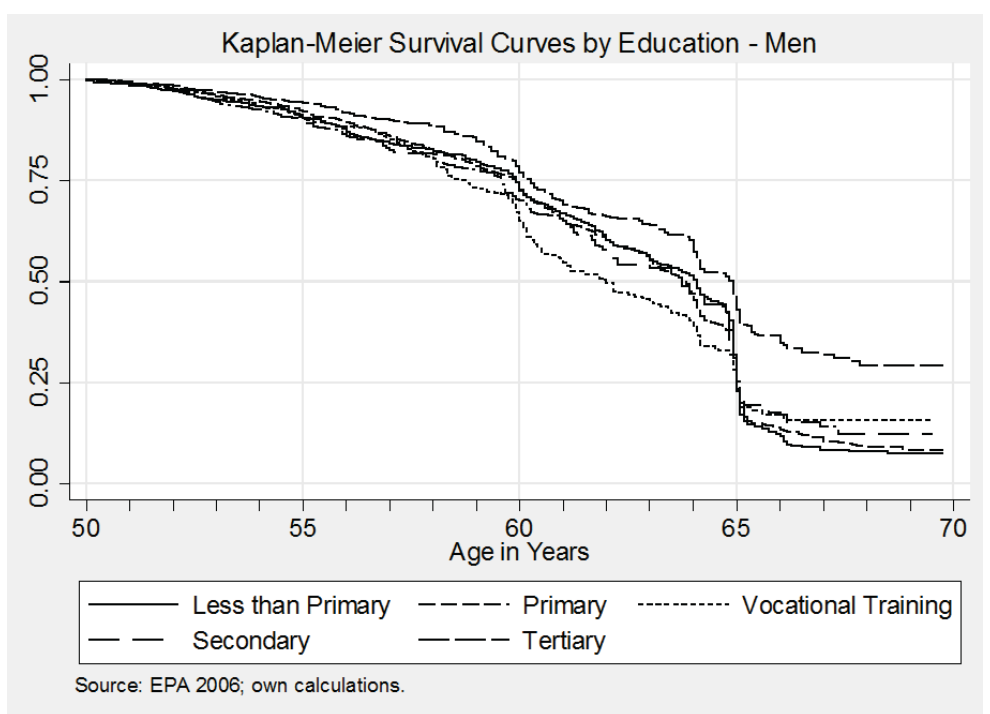

Fig. 6.5. Survivor Functions of Employment Exit in Spain by Education, Men. 


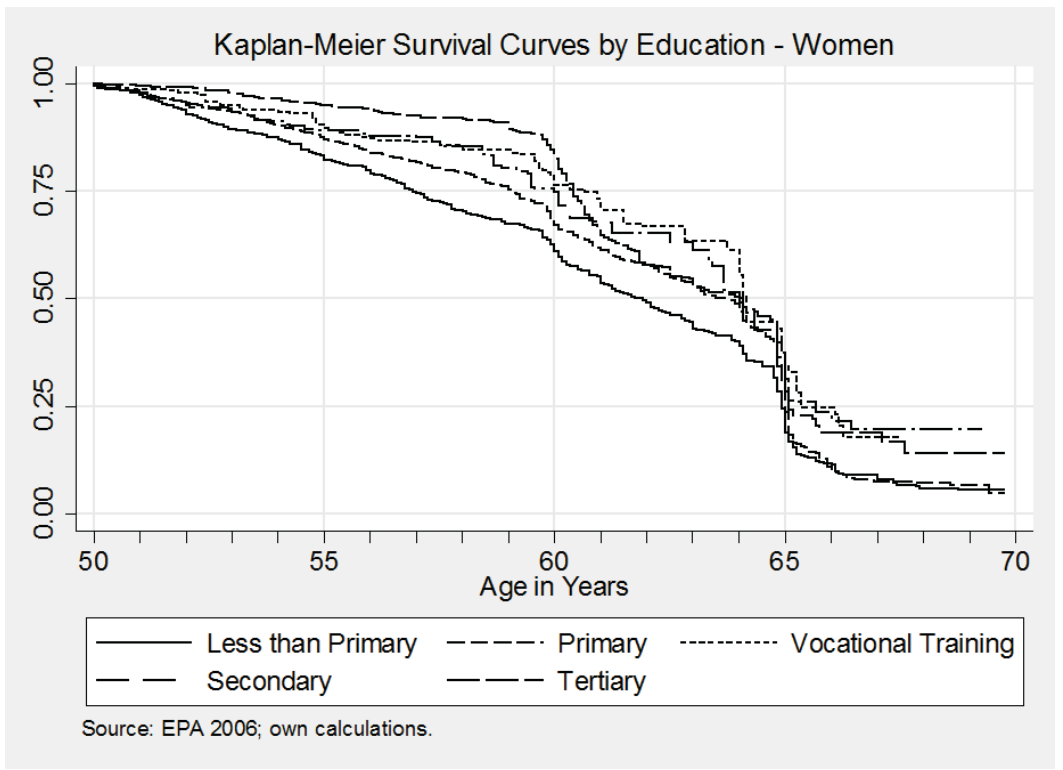

Fig. 6.6. Survivor Functions of Employment Exit in Spain by Education, Women.

higher education still remain in paid work. By contrast, workers with vocational training have the lowest survival rates, particularly between the late fifties and age 65. There is hardly a difference between those workers with secondary, primary, and less-than-primary education. These findings, which are largely in line with earlier evidence, point to a positive albeit not strictly linear influence of education on retirement ages.

For women, the pattern is quite distinct. Overall, the differences among them in terms of education are more pronounced than among men. However, only at the start of the observation window are highly educated women retiring at a lower rate. In their early sixties, many highly qualified women retire, such that from age 60 onwards, this group exhibits a lower employment retention rate than women with only secondary education or vocational training. With regard to this latter group, the finding is quite the opposite as for men: between age 60 and 64 , a lower share of women with vocational training is retired than among any of the other educational strata. The fastest retirement rate is consistently observed among women without any education.

To sum up, educational attainment is a significant predictor of men's retirement behaviour, but plays a bigger role in women's. This result should be seen in the context of other findings pointing to a very strong impact of education on women's employment rates across the whole life course (Garrido \& Chulia 2005). This juxtaposition creates a complex picture that sees less educated women (primary education or less) drop out of the labour market in 
their prime, leaving only better-educated women and the fittest among women with a low education "at risk" of retirement. This selection process is of course tied to the very definition of retirement, which - in this study as in most of the sociological literature - envisages retirement as the withdrawal from lifetime employment (cf. section 3.3.1).

\subsubsection{Multivariate Survival Analysis}

Table 6.2 shows the results of a piecewise-constant exponential model (see chap. 5 for details) on the timing of employment exit between age 58 and 65 for men. The first model illustrates the importance of occupational class for retirement timing. At 0.416 , the upper service class exhibits a transition rate that is less than half the rate of routine workers. The lower service class stays in the labour force similarly long $(H R=0.766)$, and the petite bourgeoisie (including farmers) also retire very late. The remaining classes retire earlier but do not differ significantly among themselves. While these findings are roughly in line with earlier evidence (Sánchez 2003: 231; Pérez 2006: 206), the modest transition rate exhibited by skilled manual workers is surprising, as the latter are known to be a high-risk group for early exit. We will return to this issue later in this chapter.

The second model introduces the length of the working career as a timedependent covariate, along with a set of dummies for public sector employment as well as for family situation. It turns out that for each year a man has worked his retirement propensity increases by $3 \%(H R=1.029)$. This finding was expected, because a longer contribution period is connected to higher pension entitlements. In addition, retirement is probably perceived as a more legitimate gratification the longer the working life already completed at each given age. Comparable results are reported by Muñoz et al (2007: 115). Class effects are largely unaffected by the inclusion of this set of variables, with the exception of lower sales and service workers, who now exhibit an elevated propensity to retire early.

It had been shown by previous research that public-sector employees retire later than private-sector employees (Bernardi \& Garrido 2006), a pattern that may partly be put down to compositional effects (Veira Ramos 2005). In the multivariate estimation results presented here, public-sector employment as such yields no significant effect beyond class membership. We can conclude that although at face value public-sector employees may work longer than others, this is due to the fact that relatively few low-skilled workers are employed by the state. That is, in relation to comparable workers in the private sector, Spanish civil servants are not particularly prone to exit the labour market early, as was observed for other developed countries (cf. OECD 2007).

The respondent's family situation, as indicated by marital status, and in this case, the wife's employment situation, also has its impact on retirement 
Piecewise Constant Exponential Model, Employment Exit in Spain, Men.

\begin{tabular}{|c|c|c|c|c|}
\hline ALL TRANSITIONS & \multicolumn{3}{|c|}{ Hazard Ratios } & Model 4 \\
\hline \multicolumn{5}{|l|}{$\begin{array}{l}\text { Class (ESeC) - } \\
\text { Ref.: Routine Workers }\end{array}$} \\
\hline Higher Salariat & $.416 \%$ & $.440 * *$ & $.400 * * 2$ & -- \\
\hline Lower Salariat & $.766 *$ & .898 & .909 & -- \\
\hline Intermediate Occupations & .860 & .869 & .879 & -- \\
\hline Self-employed & .512 & $.535^{\ldots}$ & $.540 \%$ & -- \\
\hline Farmers & .630 & $.645 *$ & .913 & -- \\
\hline Lower Sales\&Service & 1.265 & $1.341 * *$ & $1.279 *$ & -- \\
\hline Skilled Manual & 1.058 & 1.096 & 1.033 & -- \\
\hline Public Sector & -- & 1.015 & $1.513^{* *}$ & $1.643 \%$ \\
\hline Years Worked & -- & $1.029 \cdots$ & $1.029 \cdots$ & $1.027 \cdots$ \\
\hline $\begin{array}{l}\text { Family Situation - } \\
\text { Ref.: Married, Spouse Employed }\end{array}$ & -- & & & \\
\hline Married, Sp.Retired & -- & $1.573 \cdots$ & 1.477 & $1.555 \%$ \\
\hline Married, Sp.Inactice & -- & $1.227^{* * *}$ & $1.164^{*}$ & $1.231 \cdots$ \\
\hline Divorced & -- & .947 & .988 & 1.159 \\
\hline Widowed & -- & 1.075 & 1.080 & 1.127 \\
\hline Unmarried & -- & 1.170 & 1.215 & $1.315^{* *}$ \\
\hline \multicolumn{5}{|l|}{$\begin{array}{l}\text { Sector - } \\
\text { Ref.: Traditional Manufacturing }\end{array}$} \\
\hline Agriculture & -- & -- & $.625 \%$ & .748 \\
\hline Heavy Industry & -- & -- & 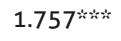 & 2.056 \\
\hline Other Manufacturing (Food, Infrastructure) & -- & -- & 1.145 & 1.230 \\
\hline Construction & -- & -- & .814 & .935 \\
\hline Trade, Transport, Hotels and Catering & -- & -- & .903 & .864 \\
\hline Inter-company services & -- & -- & .738 & .883 \\
\hline Social Services & -- & -- & $.586 \%$ & .703 \\
\hline Consumer Services & -- & -- & .769 & .858 \\
\hline
\end{tabular}


Table 6.2

Piecewise Constant Exponential Model, Employment Exit in Spain, Men.

\begin{tabular}{lcccc}
\hline ALL TRANSITIONS & Model 1 & Model 2 & Model 3 & Model 4 \\
\cline { 2 - 5 } & \multicolumn{4}{c}{ Hazard Ratios } \\
Education - \\
$\begin{array}{l}\text { Ref.: Less than Primary } \\
\text { Primary }\end{array}$ & -- & -- & -- & 1.050 \\
Vocational Training & -- & -- & -- & 1.041 \\
Secondary & -- & -- & -- & .968 \\
Tertiary & -- & -- & -- & $.648^{* \ldots+\cdots}$ \\
\hline Subjects & 4028 & 4028 & 4028 & 4028 \\
Failures & 1.740 & 1.740 & 1.740 & 1.740 \\
\hline
\end{tabular}

Source: EPA 2006; own calculations

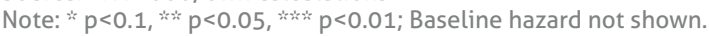

behaviour. Married men with a retired spouse exhibit a much higher retirement propensity ( $H R=1.573)$ than married workers with an active spouse (working or unemployed). Similarly, the presence of an inactive wife leads to a somewhat earlier exit, too. Among single men (divorced, widowed, unmarried), we find no significant differences with respect to retirement age. Note that these patterns are consistent with the effects of family situation on age norms reported in chapter 4 . Therefore, it can be assumed that family effects are due to the way retirement preferences are shaped by the household context.

In the third model, we add the branch of industry in which the worker is (or was) employed. It turns out that early exit from work is substantially more frequent in heavy and specialised industry (automobiles, machinery, chemical, instruments) than in traditional industry (textile, furniture, etc.). The fact that in traditional industry, which in Spain, is still a large employer, early exit schemes are less relevant than in other sectors of manufacturing partially explains why skilled manual workers are not as prone to retire early here as elsewhere. It could be speculated that low-value-added production neither permits nor requires the operation of costly early retirement programmes to renew its workforce and enhance productivity to the same extent as high-value-added manufacturing. Service-sector employees, particularly social services, appear generally to retire rather late. At the same time, late retirement is common in agriculture. The latter is responsible for neutralising the class effect corresponding to farmers. Meanwhile, all other class effects stay virtually the same. 
The final model uses categories of educational attainment instead of social class. Notably, there are no significant differences between most of the groups. Only tertiary education is connected to markedly late exit. In comparison with the descriptive findings above, we can conclude that the early exit of men with vocational training can be explained by their long employment careers, a consequence of their early entry into the labour market. In terms of its explanatory power, education is inferior to social class.

For women, the picture that emerges from table 6.3 is quite diverse in terms of class disparities. Remarkably, the female lower salariat has a tendency to exit earlier from the labour force than routine workers. As a more fine-grained analysis of occupational codes shows, this finding is driven by a high proportion of teachers. This gender-graded class effect is thus possibly due to micro-class differences. Moreover, we find that skilled workers retire much more prematurely than routine workers. But there are also strong similarities as compared to the male findings, namely the relatively late exit of the self-employed and of the higher service class. Women in intermediate occupations behave similar to women in unskilled manufacturing jobs.

To further substantiate the class-gender nexus, model 1 has been estimated for men and women together, adding a gender dummy (detailed results not displayed). Although we now know that the assumption of gender-invariant class effects is not fully accurate, it is interesting that being a woman has no significant effect in such a model beyond class membership. This supports the hypothesis that the traditional gender gap in retirement ages is related to gender segregation on the labour market.

Let us return to the results from table 6.3. We detect significant household effects in Spanish women's retirement behaviour. Again, a retired spouse increases the probability of retirement significantly, although the effect seems to be somewhat smaller than for men (HR of 1.303 versus 1.573). As among men, years of employment exert a positive influence on retirement hazards in the second model $(H R=1.018)$. The findings corresponding to the public sector are gender invariable, too.

The effects related to the sector of economic activity are more pronounced among women than among men. In all parts of the economy, women work longer than in traditional manufacturing. Ill health among female workers is a plausible explanation for this finding. Especially in the service sector and, again, in agriculture, we find markedly low retirement propensities. The final model brings about another curious finding. When including educational categories instead of class, we see that women with tertiary education, after controlling for career length, do not retire later than their less-educated counterparts. This is surprising and contrary to the findings above. Conversely, women with less than a primary education do not seem to retire especially early. Apparently, the educational gradient in retirement timing is mediated by the timing of work 
Table 6.3

Piecewise Constant Exponential Model, Employment Exit in Spain, Women.

\begin{tabular}{|c|c|c|c|c|}
\hline ALL TRANSITIONS & Model 1 & $\begin{array}{l}\text { Model } 2 \\
\text { Hazarc }\end{array}$ & $\begin{array}{l}\text { Model } 3 \\
\text { Ratios }\end{array}$ & Model 4 \\
\hline \multicolumn{5}{|l|}{$\begin{array}{l}\text { Class (ESeC) - } \\
\text { Ref.: Routine Workers }\end{array}$} \\
\hline Higher Salariat & $.172 \ldots$ & $.155^{2}$ & $.123 \cdots$ & -- \\
\hline Lower Salariat & 1.103 & 1.084 & 1.141 & -- \\
\hline Intermediate Occupations & .858 & .875 & .761 & -- \\
\hline Self-employed & $.664 \%$ & $.681 \%$ & $.641 \% *$ & -- \\
\hline Farmers & .822 & $.762 *$ & $.682 * \%$ & -- \\
\hline Lower Sales\&Service & .927 & .921 & .985 & -- \\
\hline Skilled Manual & 1.978 的学 & 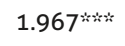 & 1.179 & -- \\
\hline Public Sector & -- & .994 & 1.372 & $1.454^{*}$ \\
\hline Years Worked & -- & $1.018 \ldots$ & $1.019 \approx$ & $1.017 \ldots$ \\
\hline $\begin{array}{l}\text { Family Situation - } \\
\text { Ref.: Married, Spouse Employed }\end{array}$ & -- & & & \\
\hline Married, Sp.Retired & -- & $1.303 \%$ & $1.294^{* * *}$ & $1.309 *$ \\
\hline Married, Sp.Inactice & -- & .989 & 1.045 & 1.102 \\
\hline Divorced & -- & 1.092 & 1.141 & 1.257 \\
\hline Widowed & -- & 1.059 & 1.049 & 1.142 \\
\hline Unmarried & -- & 1.038 & 1.010 & 1.095 \\
\hline \multicolumn{5}{|l|}{$\begin{array}{l}\text { Sector - } \\
\text { Ref.: Traditional Manufacturing }\end{array}$} \\
\hline Agriculture & -- & -- & 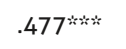 & $.413 *$ \\
\hline Heavy Industry & -- & -- & .740 & .468 \\
\hline Other Manufacturing (Food, Infrastructur & -- & -- & .661 & .657 \\
\hline Construction & -- & -- & .603 & $398^{\prime * * 1 *}$ \\
\hline Trade, Transport, Hotels and Catering & -- & -- & $.456 \%$ & $.365 \%$ \\
\hline Inter-company services & -- & -- & $.504^{* *}$ & $.481 *$ \\
\hline Social Services & -- & -- & $.304 \%$ & $323 \ldots$ \\
\hline Consumer Services & -- & -- & $357^{* \ldots *}$ & 349 \\
\hline
\end{tabular}


Piecewise Constant Exponential Model, Employment Exit in Spain, Women.

\begin{tabular}{lcccc}
\hline ALL TRANSITIONS & Model 1 & Model 2 & Model 3 & Model 4 \\
\cline { 2 - 5 } & \multicolumn{4}{c}{ Hazard Ratios } \\
$\begin{array}{l}\text { Education - } \\
\text { Ref.: Less than Primary }\end{array}$ & -- & -- & -- & .930 \\
Primary & -- & -- & -- & $.623^{*}$ \\
Vocational Training & -- & -- & -- & .891 \\
Secondary & -- & -- & -- & .938 \\
Tertiary & 1698 & 1698 & 1698 & 1698 \\
\hline Subjects & 763 & 763 & 763 & 763 \\
\hline Failures & & & & 763 \\
\hline
\end{tabular}

Source: EPA 2006; own calculations

Note: * $p<0.1, * p<0.05, * p<0.01$; Baseline hazard not shown.

entry. The fact that better-educated women have shorter working lives at a given age during their late careers fully explains the educational differences that we observe at the bivariate level.

\subsubsection{Competing Risks Models: The Social Selectivity of Pathways into Retirement}

As stated by the theoretical model outlined in chapter 3, the pathway taken to retirement is closely connected to the timing of retirement and has lasting financial consequences in old age. In the data set, pathways into retirement can be identified via two survey questions: first, the socio-economic situation after leaving the last job, which is assessed retrospectively for all retirees, taps into the dynamics of sequential retirement processes; second, respondents who claim to have moved directly from work into "retirement or early retirement" are asked additionally about their main reason for retirement. Through this survey question, individual degrees of freedom can also be addressed. In particular, I construct a four-fold typology.

Table 6.4 shows the coding scheme in detail. While differentiating between two different routes of involuntary early exit, the methodology stays close to the one applied using the SHARE data set in chapter 5. In detail, four transition modalities are distinguished: 1) conventional retirement, 2) voluntary early exit, 3) employment constraints, and 4) health-related retirement. The first category of 
Table 6.4:

Operationalisation of Retirement Modalities using EPA Data.

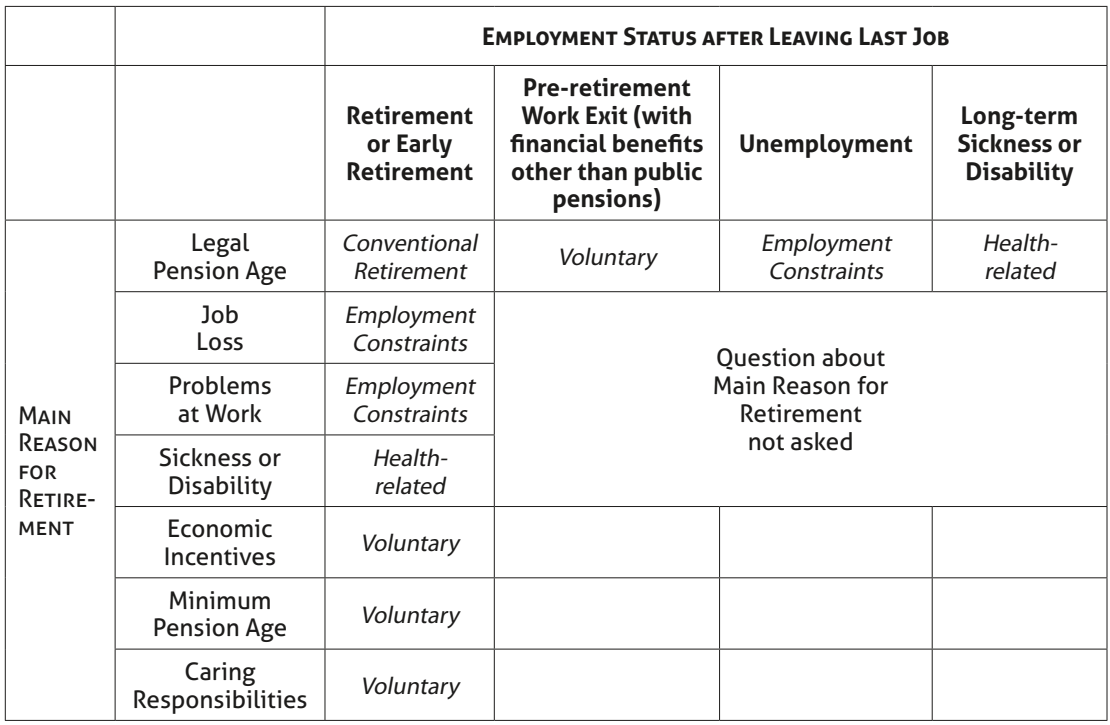

Source: own elaboration.

conventional retirement refers to individuals who report having directly entered "retirement or early retirement" after leaving their last job and those who have retired because they reached the legal retirement age. We attribute to the users of this pathway a high level of work attachment. Elderly workers who stay in the labour force due to financial constraints will also be found in this cluster.

The second category, voluntary early exit, intends to capture retirement decisions that are guided by low work attachment combined with a sufficient range of early retirement options. Many respondents in this cluster explicitly made use of some form of "pre-retirement" programme. Commonly, occupational pre-retirement plans are financed with a lump-sum severance pay, often taking advantage of the full two years of unemployment benefits. Large companies often supplement this with regular payments to the unemployed worker of between 60 and $100 \%$ of prior earnings until they reach pension age, or even for their lifetime (Muñoz et al. 2007: 104). ${ }^{85}$ Others reported having retired

85 For an interesting analysis of the various schemes of early retirement in Spain from a juridical point of view, see Desdentado and Durán (2003). According to the authors (ibid.: 56), regular compensation payments to bridge the period between work exit and pension age was only been widespread during the heavy de-industrialisation of the 1980 s. 
because of economic incentives or for reaching the "minimum pension age," i.e. 60 or 61 years, in most cases. Agency is high in this group, although less so for those who exit due to caring responsibilities.

Thirdly, we use the label employment constraints for all workers who were unemployed after their last job. In addition, workers who mention job loss or problems at work as their main reason for retirement are allocated to this category. As table 6.5 shows, this is the minority of the cases in this cluster, representing only a fourth of the cases. Given that respondents were asked for the "main reason" for their retirement, it seems likely that pressure at the workplace, possibly born out of age discrimination, drove early exit here.

The fourth transition modality is the less ambiguous, as it embraces all health-related transitions into retirement. Given diffuse perceptions connected with disability pensions and sick pay, which may distort subjectively reported information on employment status, it is preferable to include not only those retirees who explicitly mention having passed through a similar status but also those who name a disability or long-term sickness as the main reason for retirement. This is true for a third of the respondents in this group. ${ }^{86}$

Evidently, we cannot accurately subsume all possible combinations of retirement motivations and degrees of agency freedom under the proposed typology. In this sense, the categories are highly simplifying and based on clearly imperfect measurement. Nevertheless, the typology of exit modalities is arguably the best combined operationalisation of two central concepts of this study - pathways and retirement opportunities - that could be found using the data in hand.

Table 6.6 gives an overview of the importance of the various transition modalities among those Spanish men and women who retired between age 58 and 65 . According to these descriptive statistics, the majority of current retirees have completed a direct transition from work to retirement. Besides, one in five retirees have exited their last job voluntarily, e.g. with the help of an occupational pre-retirement plan. Health-related retirement via disability is also important, affecting one in six retirees. Affecting less than $9 \%$ of workers, work withdrawal via unemployment is less prevalent than expected.

$\mathbf{8 6}$ Table 6.5 also serves to contrast the methodology applied here with one used in Radl \& Bernardi (2011), in which the pathway typology is based exclusively on employment status after leaving one's last job. While the focus in that study is on the seriality of retirement transitions, the present study's approach is equally guided by the theoretical interest in the concept of agency. Overall differences are not very big, in any case. As the first column shows, most of those who take the direct route from employment to pension receipt also end up in the conventional category here. Another quarter of these respondents is found in the voluntary early exit category, and only a combined $15 \%$ are found in the other two. 
Table 6.5

Distribution of Retirement Modalities by Last Employment Status.

\begin{tabular}{|c|c|c|c|c|c|}
\hline & & \multicolumn{4}{|c|}{ EMPLOYMENT STATUS AFTER LEAVING LAST JOB } \\
\hline & & $\begin{array}{c}\text { (Early) } \\
\text { Retirement }\end{array}$ & Pre-retirement & Unemployment & $\begin{array}{l}\text { Long-term Sickness } \\
\text { or Disability }\end{array}$ \\
\hline & & \multicolumn{4}{|c|}{$\begin{array}{l}\text { Row Percentages } \\
\text { Column Percentages }\end{array}$} \\
\hline \multirow{4}{*}{$\begin{array}{l}\text { PATH- } \\
\text { WAY }\end{array}$} & $\begin{array}{c}\text { Conventional } \\
\text { Retirement }\end{array}$ & $\begin{array}{l}100 \\
58.2\end{array}$ & $\begin{array}{l}0 \\
0\end{array}$ & $\begin{array}{l}0 \\
0\end{array}$ & $\begin{array}{l}0 \\
0\end{array}$ \\
\hline & $\begin{array}{l}\text { Voluntary } \\
\text { Retirement }\end{array}$ & $\begin{array}{l}100 \\
26.6\end{array}$ & $\begin{array}{c}44.6 \\
100\end{array}$ & $\begin{array}{l}0 \\
0\end{array}$ & $\begin{array}{l}0 \\
0\end{array}$ \\
\hline & $\begin{array}{l}\text { Employment } \\
\text { Constraints }\end{array}$ & $\begin{array}{c}23.8 \\
5.0\end{array}$ & $\begin{array}{l}0 \\
0\end{array}$ & $\begin{array}{c}76.2 \\
100\end{array}$ & $\begin{array}{l}0 \\
0\end{array}$ \\
\hline & $\begin{array}{c}\text { Health-related } \\
\text { Retirement }\end{array}$ & $\begin{array}{r}34.3 \\
10.2\end{array}$ & $\begin{array}{l}0 \\
0\end{array}$ & $\begin{array}{l}0 \\
0\end{array}$ & $\begin{array}{c}65.7 \\
100\end{array}$ \\
\hline
\end{tabular}

Source: EPA 2006; own calculations.

Table 6.6

Retirement Pathways of Respondents Retiring Aged 58-65, by Sex.

\begin{tabular}{|l|c|c|c|}
\hline Pathway & Men & Women & Total \\
\hline & \multicolumn{3}{|c|}{$\begin{array}{c}\text { Number of Cases } \\
\text { Estimated Weighted Proportion in \% }\end{array}$} \\
\hline \multirow{2}{*}{ Conventional Retirement } & 611 & 285 & 896 \\
& 36.1 & 38.2 & 36.7 \\
\hline \multirow{2}{*}{ Voluntary Retirement } & 548 & 159 & 707 \\
& 32.9 & 24.7 & 30.6 \\
\hline \multirow{2}{*}{ Employment Constraints } & 234 & 73 & 307 \\
& 14.0 & 12.2 & 13.5 \\
\hline \multirow{2}{*}{ Health-related Retirement } & 275 & 167 & 442 \\
\hline \multirow{2}{*}{ Total } & 16.9 & 24.9 & 19.2 \\
\hline
\end{tabular}

Source: EPA 2006; own calculations.

There are notable differences between men and women in terms of retirement pathways. Women are offered fewer firm-sponsored plans and retire more frequently by directly taking up a pension. Health problems are far more often the reason behind women's retirement than behind men's. This difference is likely exacerbated by gender-differential mortality. Yet, contrary to our expectations, we do not observe a higher incidence of unemployment among women.

According to DiPrete (2002) the incidence of risky life events should be studied in the context of the consequences of these events. In this vein, besides 
the relative importance of a particular pathway and the corresponding labour market risks, the timing of retirement also matters. Figure 6.7 shows the KaplanMeier survival curves for the four different transitions modalities for men and women respectively. Note that other than in the survival functions above, we ignore right-censored observations here and only look at the individuals that are already retired.

The figure visualises the huge difference that exists between exit modalities in terms of retirement age. Whereas retirement occurs mostly at age 65 when taking place via conventional retirement, the other pathways are connected with a much earlier withdrawal from the labour market. On the one hand, women exit earlier than men within each given pathway; on the other, the timing consequences inherent in the various pathways differ by gender as well: for men the disability pathway clearly implies the hastiest exit, while retirement due to employment constraints follows a similar temporary pattern as voluntary early exit from work; for women, by contrast, transitions that are due to employment constraints happen as early as the health-related ones. That is, the penalty in terms of retirement age connected with employment constraints is larger for women than for men.

In the following, we discuss the results from a competing risks model that examines the socio-economic profile of the users of the respective pathways

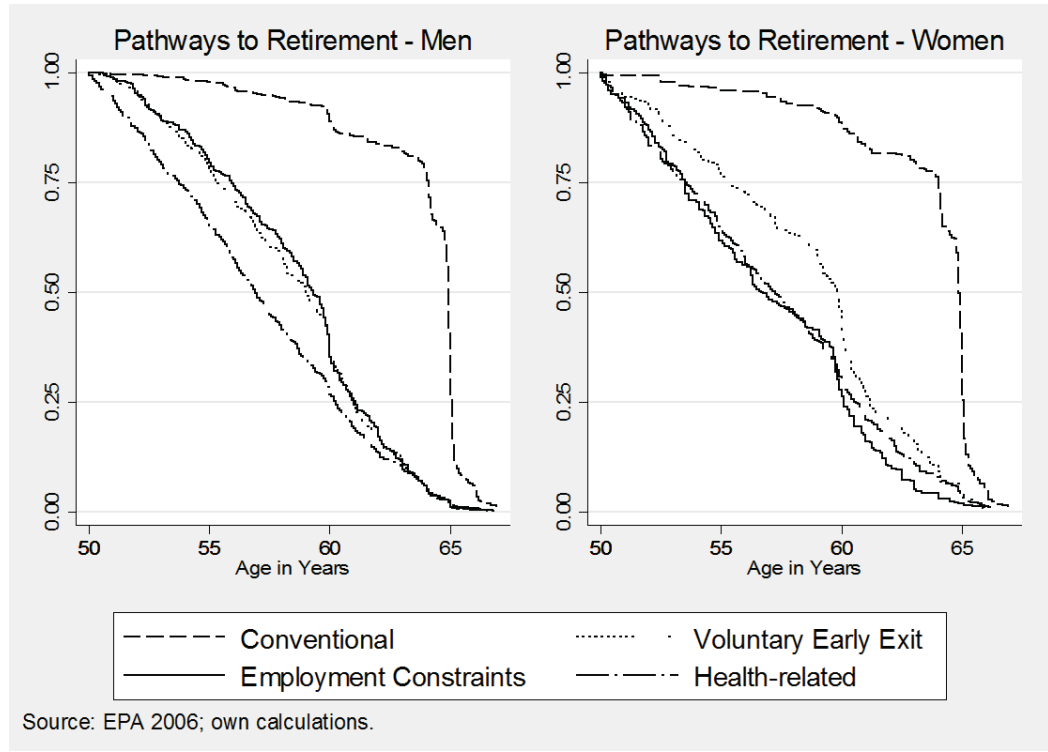

Fig. 6.7. Survivor Functions of Employment Exit in Spain by Modality and Sex, Retirees Only. 
into retirement. The reference is model 2 in the aggregated (cause-deleted) analyses. We start by looking at the factors related to conventional retirement for men, in the first column of table 6.7. The results concerning social class reaffirm the above finding concerning the (higher and lower) salariat, which has a lower transition rate into conventional retirement than unskilled workers $(H R=0.551)$. With a hazard ratio of 1.131 , the self-employed (now including farmers) do not display the usual low hazard rate, however. Accordingly, most of the independent workers stay active until the legal pension age. This high relevance of the statutory retirement age may be surprising at first sight, but it is actually straightforward given the high coverage of the self-employed under a special social-security regime, which provides an old-age pension after age 65 . Besides this, a remarkable finding is the elevated propensity $(H R=1.577)$ for conventional retirement revealed for skilled manual workers. In comparison with routine workers, they are in a better economic position to access the public early retirement pension for contributors to the pre-1967 system (mutualistas).

The second pathway refers to older workers leaving the labour market in a voluntary fashion. Notably, with a hazard ratio of 1.509, lower sales and service employees are the most prone to retire early in this way. A more fine-grained analysis revealed that this is due more to a probability than to a timing effect (for this distinction cf. section 5.3.2 and Bernardi 2001); that is, it is attributable to a high incidence of this pathway among this particular group rather than to the low retirement age of the concerned workers. While we already saw in the fourth chapter that work attachment in this group is low, it is interesting that many lower-grade service employees can economically permit themselves to retire early. Conversely, the self-employed exhibit a low propensity to withdraw from work, which adjusts to prior expectations provided that this collective seldom qualifies for any public early retirement pensions. Even so, many selfemployed could probably afford an earlier retirement if they drew on their private savings. The fact that they do not give a higher priority to family or leisure may be attributable to a high work attachment or to the endorsement of conventional age norms of retirement. Meanwhile, the finding that skilled manual workers exhibit a $24 \%$ lower sub-hazard for the voluntary early exit modality than routine workers $(\mathrm{HR}=0.759)$ is surprising insofar as for the latter, it should be particularly difficult to withdraw early under financially attractive conditions.

The next column examines retirement transitions molded by employment constraints. The evidence confirms our expectation that members of the service class rarely run the risk of leaving the labour market via unemployment $(H R=0.3)$. For evident reasons, the same is true for small employers and the selfemployed. By contrast, the working classes carry the highest risk of taking the unemployment route to retirement. The hazard ratio of 0.864 for the intermediate 
Competing Risks Model, Employment Exit in Spain, Men.

\begin{tabular}{|c|c|c|c|c|}
\hline & $\begin{array}{l}\text { CONVENTIONAL } \\
\text { RETIREMENT }\end{array}$ & $\begin{array}{l}\text { VOLUNTARY } \\
\text { RETIREMENT }\end{array}$ & $\begin{array}{l}\text { EMPLOYMENT } \\
\text { CONSTRAINTS }\end{array}$ & $\begin{array}{l}\text { HEALTH- } \\
\text { RELATED } \\
\text { RETIREMENT }\end{array}$ \\
\hline & \multicolumn{4}{|c|}{ Hazard Ratios } \\
\hline \multicolumn{5}{|l|}{$\begin{array}{l}\text { Class (ESeC) - } \\
\text { Ref.: Routine Workers }\end{array}$} \\
\hline Salariat & $.551^{* 2 x}$ & .946 & .300 \% & $.530 \%$ \\
\hline Intermediate Occupations & .836 & 1.159 & .864 & .333 的安 \\
\hline Self-employed & 1.131 & $.351 \% *$ & $.095 \% *$ & $.623 \%$ \\
\hline Lower Sales\&Service & 1.474 & $1.509 *$ & .928 & .905 \\
\hline Skilled Manual & $1.557 \ldots$ & $.759 *$ & .802 & $1.579 \%$ \\
\hline Public Sector & $1.738 \cdots$ & 1.077 & 270 的背 & .882 \\
\hline Years Worked & $1.029 \%$ & $1.041^{* 2 x}$ & 1.018 & $1.022 \%$ \\
\hline \multicolumn{5}{|l|}{$\begin{array}{l}\text { Family Situation - } \\
\text { Ref.: Married, Spouse } \\
\text { Employed }\end{array}$} \\
\hline Married, Sp.Retired & $1.892 \% *$ & $1.592 *$ & 1.446 & 1.254 \\
\hline Married, Sp.Inactice & $1.263^{*}$ & $1.580 * *$ & .870 & 1.006 \\
\hline Divorced & .802 & 1.224 & .651 & 1.668 \\
\hline Widowed & 1.164 & .872 & 1.308 & .581 \\
\hline Unmarried & 1.373 & 1.280 & .700 & 1.352 \\
\hline \multicolumn{5}{|l|}{$\begin{array}{l}\text { Baseline Hazard - } \\
\text { Ref.: Age } 58\end{array}$} \\
\hline Age 59 & $13.344^{*}$ & $1.965 \%$ & 1.798 & 1.127 \\
\hline Age 60 & 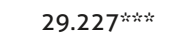 & $3.923 \ldots$ & 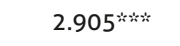 & 2.246 \\
\hline Age 61 & 14.869 & 2.362 & $2.059 \%$ & 2.250 \\
\hline Age 62 & $12.503 *$ & $2.173 \ldots$ & 2.990 & 1.555 \\
\hline Age 63 & $96.643 \ldots$ & $3.271 \%$ & $3.199 \%$ & $3.140 \cdots$ \\
\hline Age 64 & 893.959 & $3.106 \%$ & $3.143 \ldots$ & 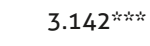 \\
\hline Age 65 & 3192.407 & $4.849 *$ & $5.261 \%$ & $5.044^{*}$ \\
\hline Subjects & 4028 & 4028 & 4028 & 4028 \\
\hline Failures & 611 & 548 & 234 & 275 \\
\hline
\end{tabular}

Source: EPA 2006; own calculations Note: * $p<0.1, * * 0.05$, *** $p<0.01$. 
occupations is not significantly different. In conclusion, leaving the labour market via unemployment is a common pathway across the mid- and lowerlevel ranks of the occupational structure, whereas managers and professionals, as well as the petite bourgeoisie, are sheltered from this risk. Interestingly, there is no apparent divide between blue-collar and white-collar workers.

Finally, there are significant class differences in what regards the healthrelated pathway. On the one hand, there is a sharp hierarchy between the working class and the service class. In particular, the salariat is $47 \%$ less prone to retire due to health problems than unskilled workers $(H R=0.530)$. The intermediate occupations also appear to stay relatively healthy throughout late working life, as they are, roughly, as prone to suffer a retirement-inducing disability as the service class. On the other hand, skilled manual workers stand out even among the working classes. They are, by a distance, the group that is most affected by career-ending disabilities. Routine workers, comprising workers in the service proletariat and non-skilled manual workers, is $58 \%$ less likely to end up in this category. Thus, physical work probably remains the risk factor that most commonly leads to health-related retirement.

Beyond social class, the competing risks framework also reveals that the employment status of the spouse only accelerates retirement through the conventional and voluntary early exit pathway (with hazard rates of 1.892 and 1.592, respectively). This is perfectly plausible, since individual choice is really the mechanism through which most household effects are supposed to work. The findings from chapter 4 clearly document this. When retirement is involuntary, in contrast, there are no significant household effects. The number of working years is positively related to the risk of early retirement via all pathways except for disability. Public-sector employment increases the propensity for conventional retirement but decreases the likelihood to exit via the employment-constraints pathway.

Table 6.8 displays the equivalent estimation results for women. There are no significant class differences to be found in what concerns conventional retirement decisions. This is partly to do with the fact that standard errors are larger because of lower case numbers. However, for voluntary early retirement transitions, we do find strong class effects. Interestingly, the female salariat displays a strong tendency to exit the labour force in this way $(H R=2.210)$. This is mostly attributable to a probability effect, i.e. many women from the service class are found in this cluster. It seems that, unlike their male counterparts, highly skilled female workers often voluntarily anticipate their retirement. Women employed in skilled manual jobs display a similar behaviour $(\mathrm{HR}=2.675)$. For the latter, this finding was expected, given a propensity towards a low work attachment (cf. chap. 4) and relatively favourable conditions for early exit. For lower sales and service employees, the findings diverge from the male pattern, as women in this class do not show any significant difference to routine workers. 
Competing Risks Model, Employment Exit in Spain, Women.

\begin{tabular}{|c|c|c|c|c|}
\hline & $\begin{array}{l}\text { CONVENTIONAL } \\
\text { RETIREMENT }\end{array}$ & $\begin{array}{l}\text { VOLUNTARY } \\
\text { RETIREMENT } \\
\text { Hazar }\end{array}$ & $\begin{array}{l}\text { EMPLOYMENT } \\
\text { CONSTRAINTS } \\
\text { Ratios }\end{array}$ & $\begin{array}{c}\text { HEALTH- } \\
\text { RELATED } \\
\text { RETIREMENT }\end{array}$ \\
\hline \multicolumn{5}{|l|}{$\begin{array}{l}\text { Class (ESeC) - } \\
\text { Ref.: Routine Workers }\end{array}$} \\
\hline Salariat & .760 & $2.210 \%$ & .529 & $.424 \%$ \\
\hline Intermediate Occupations & .662 & 1.354 & 2.320 & $.299 \%$ \\
\hline Self-employed & 1.044 & .762 & $.075^{* \ldots * m}$ & $.594^{\mathrm{k}}$ \\
\hline Lower Sales\&Service & .869 & 1.136 & 1.553 & $.550 *$ \\
\hline Skilled Manual & 1041.000 & $2.675^{* * t}$ & 3.146 & 1.866 \\
\hline Public Sector & $2.185^{\ldots}$ & .996 & $.220 \%$ & 1.306 \\
\hline Years Worked & $1.012 *$ & $1.029 * \cdots$ & $1.032 \cdots$ & $1.013^{*}$ \\
\hline \multicolumn{5}{|c|}{$\begin{array}{l}\text { Family Situation - } \\
\text { Ref.: Married, Spouse Employed }\end{array}$} \\
\hline Married, Sp.Retired & 1.517 & 1.544 & .657 & 1.392 \\
\hline Married, Sp.Inactice & .678 & 1.330 & .923 & 1.022 \\
\hline Divorced & .910 & 1.483 & 1.035 & .917 \\
\hline Widowed & 1.194 & .799 & .615 & 1.162 \\
\hline Unmarried & 1.362 & 1.058 & 1.037 & .894 \\
\hline \multicolumn{5}{|l|}{$\begin{array}{l}\text { Baseline Hazard - } \\
\text { Ref.: Age } 58\end{array}$} \\
\hline Age 59 & $8.852 \%$ & $4.448 \ldots$ & $2.515^{*}$ & 1.265 \\
\hline Age 60 & $26.059 \ldots$ & $10.932^{2}$ & $4.230 \cdots$ & 1.468 \\
\hline Age 61 & $10.463^{* \cdots}$ & $5.563 \ldots$ & $3.968 \%$ & 1.266 \\
\hline Age 62 & 7.257 & $4.787^{* * *}$ & 2.720 & 1.624 \\
\hline Age 63 & $44.092 \ldots$ & $7.474^{\cdots}$ & .734 & 1.672 \\
\hline Age 64 & 587.889 & $11.083^{*}$ & $3.392 \%$ & $2.255^{2}$ \\
\hline Age 65 & $2232.136 \%$ & 18.650 & $8.735^{\ldots}$ & $6.782 \ldots$ \\
\hline Subjects & 1698 & 1698 & 1698 & 1698 \\
\hline Failures & 285 & 159 & 73 & 167 \\
\hline
\end{tabular}

Source: EPA 2006; own calculations Note: $" p<0.1, * p<0.05$, * $* x<0.01$. 
Accordingly, if there are any early retirement privileges connected to this kind of jobs, then they are confined to men.

The next set of estimates, concerning retirement induced by employment constraints, are notable insofar as routine workers are surprisingly not among the high-risk groups. Quite the contrary, both for the skilled workers and the intermediate occupations, we find transition rates that are more than twice as high (HR of 3.146 and 2.320). This is due to the higher incidence of this pathway rather than to a lower retirement age among the users of the pathway. Given the close connection between skill levels and unemployment, it is plausible that this pattern is partly related to an instrumental usage of the unemployment pathway. Compared to routine workers, everybody has a lower risk to retire via the health-related pathway. The only exception is skilled manual workers, who may carry a higher risk $(H R=1.866)$. Thus, also among women, the difference between manual and non-manual jobs is decisive for the disability route into retirement.

Like for men, being employed in the public sector works as a safeguard against being laid off and thus decreases the risk of retiring via the employmentconstraints pathway. Public sector employees predominantly move directly from work into the pension system. Although family situation exerts no significant effects, the coefficients for the female sample point in the same direction as men's point.

We can therefore conclude that class effects at the bottom of the hierarchy work very differently for men and women. In re-assessing the difference between skilled workers and routine workers, we find that among women, the low retirement age of the former is driven by more frequent voluntary early exit and, strangely, stronger employment constraints. Among men, skilled manual workers carry a higher risk of suffering a retirement-accelerating disability, but in terms of their overall retirement timing, they compensate for this disadvantage with a higher incidence of conventional late retirement. With regard to lower-sales and service workers, among women, the retirement behaviour of this collective hardly differs from routine workers. By contrast, among men, this class emerges as privileged when compared to the other members of the working class.

We furthermore find gender disparities with regard to the differential retirement pathways of the working class. Recall that for men there were no considerable differences between skilled and unskilled manual workers. However, among female skilled workers, early exit is more frequently observed than among female routine manual workers via all pathways except for the (often firm-sponsored) voluntary early exit pathway. In sum, class effects in retirement behaviour work quite differently among men and women, especially at the bottom of the occupational hierarchy. 


\subsubsection{Duration Selection Models: Controlling for Inactivity}

In the remainder of the chapter, the above referred selection process is explicitly taken into account in the statistical analysis. This is important as our estimates may be distorted by the circumstance that economic inactivity at age 50 - the moment at which our (retrospective) observation of retirement processes begins - probably depends on individual characteristics, which influence the timing of retirement. Correspondingly, a systematic attempt shall be made to assess the size of selection bias in the foregoing analyses. Yet, the data in hand do not allow us to model the entire process of mid-life employment decisions in a strictly causal fashion. What is more, finding a merely technical solution to the problem of selection effects in event-history models is all but trivial. How can we adjust our estimates to the fact that the population at risk of retirement is not representative of the whole elderly population?

The correction of selection processes in duration models has been at the cutting edge of methodological innovation during recent years (Wu 2003: 496). The estimator proposed by Boehmke, Morey, and Shannon (2006) allows modelling duration selection models in continuous time. Based on the simultaneous estimation of a selection model and a survival model, their approach takes into account the differential probability of enrolment when analysing the risk factors related to the duration of a state until a given event. Beyond its value for statistics, a key virtue of the contribution by Boehmke et al. is to make the estimator available for use within a standard software package (Stata). However, there is an important drawback to this estimator in the present context as well. Namely, it does not allow for time-varying covariates in the outcome equation. This means that our favourite model, the piecewise constant exponential model, is not viable in this framework. In consequence, two kinds of adjustments are necessary in order to integrate the selection process into our models. Firstly, we have to rely on a fully parametric specification of survival time rather than the semi-parametric PCEM. And secondly, it is necessary to implement a number of covariates in time-constant instead of in time-varying form.

As an alternative to the PCEM, I have chosen the flexible Weibull model. ${ }^{87}$ The years of lifetime employment are converted into a time-constant covariate that now refers to the approximate value at age 50. I have also had to remove the information on the employment situation of spouses (if applicable); instead, a categorical variable indicates the respondent's marital status at the time of the interview. Given these potentially influential modifications, before advancing

$\mathbf{8 7}$ The Weibull model was also used as alternative modelling approach in section 5.5.5. 
to a duration selection model, it was important to verify that the non-weighted Weibull model with a single spell per analysis subject delivers equivalent results to the PCEM used above. The same models as in the last section are estimated again using the Weibull model. As it turns out (results not shown), all coefficients stay virtually identical. ${ }^{88}$ The single-spell Weibull model thus seems an adequate basis on which to build a duration selection model of retirement timing.

As noted above, eligibility for the ad-hoc module depends on subjects' being economically active at age 50 . Moreover, we restricted the sample to those persons who had more than ten years of employment experience. All these issues imply a systematic selection of the population under study. Besides, there are supposedly non-random patterns of non-response for the ad-hoc module of the questionnaire, for which participation was not obligatory. In the following, the level of educational attainment of the respondents will be adopted as a selection criterion for the inclusion in the risk set. That is, we assume that the question of whether a person is part of our analysis sample is solely a matter of education. Of course, modelling the enrolment into the duration analysis exclusively in terms of education supposes a high degree of simplification. Specifically in the case of the women, it would have been preferable to include the number of children in the selection equation, but unfortunately, this information is not available in the EPA data. Moreover, parsimony was critical given the computational intensity of the simultaneous estimations in question.

Tables 6.9 and 6.10 show the estimation results for men and women respectively. As becomes apparent from the upper panel of the two tables, entry into late careers depends heavily on the level of education. Importantly, there is a large difference in enrolment between respondents without full primary education and those with tertiary education. The latter are most likely to enter the risk set, followed by respondents with vocational training. In general, the educational gradient is larger for women than for men. It can be inferred from the related research that this is due to the fact that female inactivity is often the consequence of task specialisation in the household (cf. e.g. Bernardi 1999; Blossfeld \& Drobniĉ 2001). On average, Spanish women from the cohorts in question clearly have less education than Spanish men.

$\mathbf{8 8}$ The estimated baseline hazard is monotonically increasing, which is similar to the result in the stepwise function of the PCEM, in which only the peak at age 60 represented a discontinuity in the baseline hazard. NB: based on these results, the critical reader could be tempted to doubt the necessity of using complex models in general. However, it is also true that we would not know if a simpler model would suffice had we not first estimated the most adequate, complex model with time-varying covariates. 
Duration Selection Model (Weibull), Timing of Employment Exit in Spain, Men.

\begin{tabular}{|c|c|c|c|c|}
\hline \multirow[t]{2}{*}{ ALL TRANSITIONS } & Model 1 & Model 2 & Model 3 & Model 4 \\
\hline & \multicolumn{4}{|c|}{$\operatorname{Exp}(\beta)$} \\
\hline \multicolumn{5}{|l|}{ SELECTION } \\
\hline \multicolumn{5}{|l|}{$\begin{array}{l}\text { Education - } \\
\text { Ref.: Less than Primary }\end{array}$} \\
\hline Primary & $1.262 \%$ & $1.206 \%$ & $1.209 \%$ & $1.213 \% *$ \\
\hline Vocational Training & $1.253 \cdots$ & $1.199 \% *$ & $1.205^{* ⿰ 幺 幺}$ & $1.213 \%$ \\
\hline Secondary & $1.183 \ldots$ & $1.138 \ldots$ & $1.141^{* ⿰ 幺 幺}$ & 1.145 \\
\hline Tertiary & $1.432 \%$ & $1.389 \%$ & $1.391^{* ⿰ 幺 幺}$ & $1.391 \%$ \\
\hline \multicolumn{5}{|l|}{ DURATION } \\
\hline \multicolumn{5}{|l|}{$\begin{array}{l}\text { Class (ESeC) - } \\
\text { Ref.: Routine Workers }\end{array}$} \\
\hline Higher Salariat & $.335 \%$ & $.399 *$ & $.357 \cdots$ & -- \\
\hline Lower Salariat & .883 & .902 & .905 & -- \\
\hline Intermediate Occupations & .861 & .811 & .801 & -- \\
\hline Self-employed & $.468 \%$ & $.474^{* \ldots * *}$ & $.489 \cdots$ & -- \\
\hline Farmers & $.588 \% * \%$ & $.600 \%$ & .908 & -- \\
\hline Lower Sales\&Service & $1.194^{+}$ & $1.384 * *$ & $1.316 *$ & -- \\
\hline Skilled Manual & 1.075 & 1.098 & 1.020 & -- \\
\hline Public Sector & -- & .960 & $1.666^{* ⿰ 幺}$ & $1.620 \% *$ \\
\hline Years Worked & -- & 1.031 然 & $1.029 \div$ & $1.022 \%$ \\
\hline $\begin{array}{l}\text { Marital Status - } \\
\text { Ref.: Married }\end{array}$ & -- & & & \\
\hline Divorced & -- & 1.034 & 1.096 & 1.142 \\
\hline Widowed & -- & .817 & .877 & .971 \\
\hline Never married & -- & .815 & .860 & .835 \\
\hline \multicolumn{5}{|c|}{$\begin{array}{l}\text { Sector - } \\
\text { Ref.: Traditional Manufacturing }\end{array}$} \\
\hline Agriculture & -- & -- & $.570 \% *$ & $.705^{\ldots *}$ \\
\hline Heavy Industry & -- & -- & 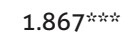 & $2.275 \ldots$ \\
\hline Other Manufacturing & -- & -- & 1.167 & 1.268 \\
\hline Construction & -- & -- & .779 & .913 \\
\hline $\begin{array}{l}\text { Trade, Transport, } \\
\text { Hotels and Catering }\end{array}$ & -- & -- & .854 & .829 \\
\hline
\end{tabular}


Table 6.9

Duration Selection Model (Weibull), Timing of Employment Exit in Spain, Men.
Duration

\begin{tabular}{|c|c|c|c|c|}
\hline \multirow[t]{2}{*}{ ALL TRANSITIONS } & Model 1 & Model 2 & Model 3 & Model 4 \\
\hline & \multicolumn{4}{|c|}{$\operatorname{Exp}(\beta)$} \\
\hline Inter-company services & -- & -- & .771 & .933 \\
\hline Social Services & -- & -- & $.515^{2}$ & $.625^{*}$ \\
\hline Consumer Services & -- & -- & $.714^{*}$ & .803 \\
\hline \multicolumn{5}{|l|}{$\begin{array}{l}\text { Education - } \\
\text { Ref.: Less than Primary }\end{array}$} \\
\hline Primary & -- & -- & -- & 1.054 \\
\hline Vocational Training & -- & -- & -- & 1.040 \\
\hline Secondary & -- & -- & -- & .971 \\
\hline Tertiary & -- & -- & -- & $.630 \cdots$ \\
\hline p (Duration Dependence) & 28.741 & 29.150 & 30.028 & 29.283 \\
\hline rho (Error Correlation) & -.2245 & -.2221 & -.2205 & -.2218 \\
\hline Subjects & 16417 & 16417 & 16417 & 16417 \\
\hline N Entered Duration Analysis & 4.028 & 4.028 & 4.028 & 4.028 \\
\hline Failures & 1.740 & 1.740 & 1.740 & 1.740 \\
\hline
\end{tabular}

Source: EPA 2006; own calculations Note: * $p<0.1, * p<0.05$, *** $p<0.01$.

As for the estimated hazard rates displayed in the lower panel, it is striking that these hardly change with respect to the results presented in section 6.5.3. This is true for both men and women. Most importantly, all class effects on retirement timing are practically identical.

Considering the size of the education-based selection effect, there could well have been more important changes in the estimates. That this is not the case lends additional credibility to the results presented above.

It is also worth mentioning the results for the parameter rho, which indicates the estimated error correlation between the selection and the duration equation. For both sexes, we find a strong negative correlation between the error terms of both equations. This suggests the existence of at least one unobserved factor that is positively related to employment in later life and negatively to the retirement rate. This demonstrates homology among the employment exit processes before and after age 58. Factors linked to increased employment participation leading to that age also enhance employment retention thereafter. 
Duration Selection Model (Weibull), Timing of Employment Exit in Spain, Women.

\begin{tabular}{|c|c|c|c|c|}
\hline \multirow[t]{2}{*}{ ALL TRANSITIONS } & Model 1 & Model 2 & Model 3 & Model 4 \\
\hline & \multicolumn{4}{|c|}{$\operatorname{Exp}(\beta)$} \\
\hline \multicolumn{5}{|l|}{ SELECTION } \\
\hline \multicolumn{5}{|l|}{$\begin{array}{l}\text { Education - } \\
\text { Ref.: Less than Primary }\end{array}$} \\
\hline Primary & $1.129^{*}$ & $1.129^{* \cdots * * ;}$ & $1.129 \cdots$ & $1.129 \%$ \\
\hline Vocational Training & $1.445 \%$ & 1.444 & $1.445^{\cdots \cdots}$ & $1.441^{\cdots}$ \\
\hline Secondary & $1.298 \%$ & $1.298 \cdots$ & $1.297^{* \cdots *}$ & 1.300 \\
\hline Tertiary & $1.930 \cdots$ & 1.930 & 1.930 & $1.931^{* \ldots}$ \\
\hline \multicolumn{5}{|l|}{ DURATION } \\
\hline \multicolumn{5}{|l|}{$\begin{array}{l}\text { Class (ESeC) - } \\
\text { Ref.: Routine Workers }\end{array}$} \\
\hline Higher Salariat & $.182 \ldots$ & .163 & $.130 \ldots$ & -- \\
\hline Lower Salariat & 1.138 & 1.006 & 1.167 & -- \\
\hline Intermediate Occupations & .908 & .858 & .738 & -- \\
\hline Self-employed & $.653^{* \ldots}$ & $.672^{2 n}$ & $.600 \cdots$ & -- \\
\hline Farmers & .814 & .763 & .660 & -- \\
\hline Lower Sales\&Service & .886 & .854 & .944 & -- \\
\hline Skilled Manual & $2.257 \ldots$ & 2.267 & 1.237 & -- \\
\hline Public Sector & -- & 1.117 & $1.825 \%$ & $1.878 \cdots$ \\
\hline Years Worked & -- & 1.017 & $1.017 \ldots$ & $1.015 \ldots$ \\
\hline $\begin{array}{l}\text { Marital Status - } \\
\text { Ref.: Married }\end{array}$ & -- & & & \\
\hline Divorced & -- & .929 & .893 & .938 \\
\hline Widowed & -- & 1.175 & 1.207 & 1.314 \\
\hline Never married & -- & .949 & .962 & 1.026 \\
\hline \multicolumn{5}{|c|}{$\begin{array}{l}\text { Sector - } \\
\text { Ref.: Traditional Manufacturing }\end{array}$} \\
\hline Agriculture & -- & -- & $.445^{\cdots}$ & $.373 \ldots$ \\
\hline Heavy Industry & -- & -- & .886 & .618 \\
\hline Other Manufacturing & -- & -- & .707 & .681 \\
\hline Construction & -- & -- & .560 & .343 \\
\hline $\begin{array}{l}\text { Trade, Transport, } \\
\text { Hotels and Catering }\end{array}$ & -- & -- & $.432 \%$ & $.330 \%$ \\
\hline Inter-company services & -- & -- & $.418 \cdots$ & $.391 \%$ \\
\hline Social Services & -- & -- & $.218 \ldots$ & $.227^{2}$ \\
\hline
\end{tabular}


Table 6.10

Duration Selection Model (Weibull), Timing of Employment Exit in Spain, Women.
Dution

\begin{tabular}{|c|c|c|c|c|}
\hline \multirow[t]{2}{*}{ ALL TRANSITIONS } & Model 1 & Model 2 & Model 3 & Model 4 \\
\hline & \multicolumn{4}{|c|}{$\operatorname{Exp}(\beta)$} \\
\hline Consumer Services & -- & -- & $318^{2}$ & .303 \\
\hline \multicolumn{5}{|l|}{$\begin{array}{l}\text { Education - } \\
\text { Ref.: Less than Primary }\end{array}$} \\
\hline Primary & -- & -- & -- & .943 \\
\hline Vocational Training & -- & -- & -- & $.580 \%$ \\
\hline Secondary & -- & -- & -- & .975 \\
\hline Tertiary & -- & -- & -- & 1.007 \\
\hline p (Duration Dependence) & 28.50053 & 28.96893 & 29.72879 & 29.463 \\
\hline rho (Error Correlation) & -.1960 & -.1939 & -.1899 & -.1896 \\
\hline Subjects & 20.349 & 20.349 & 20.349 & 20.349 \\
\hline $\mathrm{N}$ entered Duration Analysis & 1.698 & 1.698 & 1.698 & 1.698 \\
\hline Failures & 763 & 763 & 763 & 763 \\
\hline
\end{tabular}

Source: EPA 2006; own calculations

Note: $* p<0.1, * p<0.05$, $* * 0<0.01$.

It is furthermore comforting that the error correlation never reaches the allowed upper or lower thresholds; the tolerated interval lies between 0.25 and -0.25 (Boehmke et al. 2006). The fact that rho does not change significantly across specifications makes us confident of the robustness of the results.

Note that the competing risk model was also re-estimated within the duration selection framework. The results are not displayed because no new insights emerged from this exercise. Suffice it to say that there are no relevant deviations from the generic model presented in the forgoing section 6.5.4.

\subsection{Summary}

In this chapter, we have analysed the Spanish Labour Force Survey with respect to (1) the prevalence of different pathways into retirement, (2) the influence of socio-economic characteristics on the timing of the work-exit transition, and (3) the individual risk factors related to various retirement modalities.

A trend towards early retirement has unfolded later in Spain than in other Western European countries and has recently come to a halt. Before the current crisis, it seemed that retirement ages were on the rise again. Unfortunately, within the context of this study, it is not possible to assess whether the observed 
reversal is due to the modifications of pensions and employment regulations or to the entry of better-educated cohorts into late working life, or to both. In any case, the ongoing changes in the Spanish labour market make the analysis of retirement behaviour in Spain a rewarding endeavour.

As regards our main theme of social stratification in retirement, one of the key contributions of this chapter has been to include women, who have often been neglected in previous studies on Spain, in the analysis of retirement behaviour. Surprisingly, women do not retire much earlier than men, although the proportion of women who are economically active is much lower at any age. A powerful selection process takes place in Spain during the mid-career phase, with the consequence that only a sub-group of women gets to experience a late career. These work-oriented women do not retire much later than men, although the patterns of social stratification among them turn out to be quite different. In fact, occupational class disparities in terms of retirement behaviour are shaped quite distinctly among female and male workers respectively. Gender differences in class effects on retirement are especially pronounced at the bottom of the occupational hierarchy. For instance, women in lower sales and service jobs do not enjoy the same surprisingly favourable retirement opportunities as their male counterparts. Considering the increase in legal pension age coming into effect in 2013, such evidence makes it appear likely that women will in the future incur notable pension reductions.

For Spanish men, our hypothesis of pronounced class disparities in the timing of retirement has been confirmed by the empirical analyses. The service class is largely sheltered from late-career risks. With labour market push factors practically neutralised for the core work force through heavy employment protection, the comparatively strong work incentives embedded in the Spanish pension system become prevalent. As regards the 2011 pension reform, this means that high-skilled employees are probably well able to adapt their retirement behaviour to the changed actuarial adjustment scheme. On the contrary, skilled and unskilled manual workers exhibit a high propensity to leave the labour market early because of an increased risk of unemployment and disability during their late career. These two groups, as well as to a lesser extent the large class of lower sales and service workers, will likely be adversely affected by the possible increase in the legal pension age.

The self-employed, small proprietors, and agricultural workers in Spain stay in the labour market longer than dependently employed persons. In fact, the estimated hazard rate is nearly identical to the corresponding rate derived from SHARE in the previous chapter. Evidently, the mechanisms that otherwise bring about early exit from work do not operate in the same way for autonomous workers. If it is not for reasons of ill health, these workers stay in work a relatively long time. Their independence as employers and the possibility to gradually reduce working hours allows them to adapt to the increase of the legal pension 
age. Although the finding concerning the self-employed is in line with evidence from other countries, it gains additional salience in the Spanish context, where the share of self-employed is exceptionally high. The promotion of selfemployment could possibly be a viable instrument for policy makers in other countries to enhance the prolongation of working lives. 